\title{
Apolipoprotein E Deficiency Causes Endothelial Dysfunction in the Mouse Retina
}

\author{
Jenia Kouchek Zadeh 마, ${ }^{1}$ Mayagozel B. Zhutdieva, ${ }^{1}$ Panagiotis Laspas, ${ }^{1}$ Can Yuksel, ${ }^{1}$ \\ Aytan Musayeva, ${ }^{1}$ Norbert Pfeiffer, ${ }^{1}$ Christoph Brochhausen $\mathbb{D}^{2,3}$ Matthias Oelze, ${ }^{4}$ \\ Andreas Daiber $\left(\mathbb{D},{ }^{4}\right.$ Ning Xia, ${ }^{5}$ Huige Li $\left(\mathbb{D},{ }^{5}\right.$ and Adrian Gericke $\mathbb{D}^{1}$ \\ ${ }^{1}$ Department of Ophthalmology, University Medical Center, Johannes Gutenberg University Mainz, Langenbeckstr. 1, \\ 55131 Mainz, Germany \\ ${ }^{2}$ Institute of Pathology, University Medical Center, Johannes Gutenberg University Mainz, Langenbeckstr. 1, 55131 Mainz, Germany \\ ${ }^{3}$ Institute of Pathology, University of Regensburg, Franz-Josef-Strauss-Allee 11, 93053 Regensburg, Germany \\ ${ }^{4}$ Center of Cardiology 1, Molecular Cardiology, University Medical Center, Johannes Gutenberg University Mainz, Langenbeckstr. 1, \\ 55131 Mainz, Germany \\ ${ }^{5}$ Department of Pharmacology, University Medical Center, Johannes Gutenberg University Mainz, Obere Zahlbacher Str. 67, \\ 55131 Mainz, Germany
}

Correspondence should be addressed to Jenia Kouchek Zadeh; je.kouchek@hotmail.de

Received 10 June 2019; Revised 25 September 2019; Accepted 16 October 2019; Published 12 November 2019

Academic Editor: Sonia de Pascual-Teresa

Copyright (c) 2019 Jenia Kouchek Zadeh et al. This is an open access article distributed under the Creative Commons Attribution License, which permits unrestricted use, distribution, and reproduction in any medium, provided the original work is properly cited.

Objective. Atherogenic lipoproteins may impair vascular reactivity consecutively causing tissue damage in multiple organs via abnormal perfusion and excessive reactive oxygen species generation. We tested the hypothesis that chronic hypercholesterolemia causes endothelial dysfunction and cell loss in the retina. Methods. Twelve-month-old apolipoprotein E-deficient (ApoE-/-) mice and age-matched wild-type controls were used in this study ( $n=8$ per genotype for each experiment). Intraocular pressure, blood pressure, and ocular perfusion pressure were determined. Retinal arteriole responses were studied in vitro, and reactive oxygen and nitrogen species were quantified in the retinal and optic nerve cryosections. The expression of the lectin-like oxidized low-density lipoprotein receptor-1 (LOX-1) and the NADPH oxidase isoforms, NOX1, NOX2, and NOX4, were determined in retinal cryosections by immunofluorescence microscopy. Pro- and antioxidant redox genes were quantified in retinal explants by PCR. Moreover, cell number in the retinal ganglion cell layer and axon number in the optic nerve was calculated. Results. Responses to the endothelium-dependent vasodilator, acetylcholine, were markedly impaired in retinal arterioles of ApoE-/- mice $(P<0.01)$. LOX-1 $(P=0.0007)$ and NOX2 $(P=0.0027)$ expressions as well as levels of reactive oxygen species $(P=0.0022)$ were increased in blood vessels but not in other retinal structures. In contrast, reactive nitrogen species were barely detectable in both mouse genotypes. Messenger RNA for HIF-1 $\alpha$, VEGF-A, NOX1, and NOX2, but also for various antioxidant redox genes was elevated in the retina of ApoE-/- mice. Total cell number in the retinal ganglion cell layer did not differ between ApoE-/- and wild-type mice $(P=0.2171)$. Also, axon number in the optic nerve did not differ between ApoE-/- and wild-type mice $(P=0.6435)$. Conclusion. Apolipoprotein E deficiency induces oxidative stress and endothelial dysfunction in retinal arterioles, which may trigger hypoxia in the retinal tissue. Oxidative stress in nonvascular retinal tissue appears to be prevented by the upregulation of antioxidant redox enzymes, resulting in neuron preservation.

\section{Introduction}

Hypercholesterolemia is a main risk factor for atherosclerosis and thus a primary cause of cardiovascular organ dysfunction [1-3]. Critical molecular events in atherogenesis are oxidative alterations of lipoproteins and phospholipids, activation of endothelial cells, and infiltration of the vascular wall by macrophages, which is facilitated by reactive oxygen species (ROS) $[4,5]$. In the human retina, elevated serum cholesterol levels have been associated with reduced 
retinal vascular hyperemic responses to flicker light stimulation $[6,7]$. Also, familial risk for cardiovascular disease was reported to be associated with alterations in the retinal vascular function [8]. In addition, hypercholesterolemia has been linked to the pathogenesis of retinal artery and vein occlusion, which constitute major reasons for severe visual impairment and blindness [9-11]. Moreover, a recent meta-analysis reported on an association between hyperlipidemia and an increased risk of glaucoma [12], which is one of the leading causes of vision impairment worldwide characterized by progressive loss of retinal ganglion cells (RGCs), visual field defects, and specific morphological changes of the optic nerve [13-15]. One of the heavily discussed risk factors for glaucoma is impaired ocular perfusion, and vascular endothelial dysfunction is suggested to contribute to abnormalities in ocular perfusion observed in glaucoma patients $[16,17]$. Hence, hypercholesterolemia might be linked to glaucoma via inducing vascular endothelial dysfunction in the eye. Despite these findings, the specific effects of hypercholesterolemia on retinal vascular function are unknown at the molecular level. Moreover, it remains to be established whether chronic hypercholesterolemia has an influence on RGC viability. Hence, the aim of the present study was to test the hypothesis that chronic hypercholesterolemia affects retinal arteriole reactivity and RGC survival. We used apolipoprotein E-deficient mice (ApoE-/-) for our studies, because they develop spontaneous severe hypercholesterolemia and atherosclerotic lesions in various blood vessels similar to those found in humans [18-20].

\section{Materials and Methods}

2.1. Animals. All animals were treated in accordance with the guidelines of EU Directive 2010/63/EU for animal experiments and were approved by the Animal Care Committee of Rhineland-Palatinate, Germany. Mice deficient in the gene coding for apolipoprotein E (ApoE-/-) and agematched wild-type controls (C57BL/6J) were obtained from The Jackson Laboratory, Bar Harbour, ME, USA. Male mice were fed with a standard rodent chow (Altromin, Lage, Germany) and used for experiments at the age of 12 months. In a previous study using mice from our mouse stock and the same chow, plasma low-density lipoprotein (LDL) and total cholesterol levels were increased by more than 5-fold in 6-month-old ApoE-/- mice compared to wild-type controls [21]. Mice were housed under standardized conditions ( 12 hours light/dark cycle, temperature of $22 \pm 2^{\circ} \mathrm{C}$, humidity of $55 \pm 10 \%$, and free access to food and tap water).

2.2. Measurement of Intraocular Pressure, Blood Pressure, and Cholesterol. Intraocular pressure (IOP) was measured noninvasively in conscious mice ( $n=8$ per genotype) using the Icare ${ }^{\circledR}$ TONOLAB rebound tonometer (Bon Optic, Lübeck, Germany) designed for mice and rats. Before each examination, topical anaesthesia (proparacaine 0.5\% eye drops, URSAPHARM Arzneimittel GmbH, Saarbrücken, Germany) was applied onto the ocular surface. Per eye, 12
IOP values were taken and the overall mean of all 24 measurements was calculated for each mouse. Blood pressure measurements with a computerized tail-cuff system (CODA ${ }^{\circledR}$ Monitor, Kent Scientific, Torrington, CT, USA) were conducted in conscious restrained mice ( $n=8$ per genotype). Before measurement, mice were trained for two consecutive days to become acclimatized to the procedure. Mice were placed in restraint tubes to prevent excessive movement during measurement and placed on a warming platform (32$35^{\circ} \mathrm{C}$ ). After tails were cuffed, an acclimatization time of 5 minutes allowed mice to warm up before the start of the experiment. Each session consisted of 20 measuring cycles, of which the first 5 cycles were used for acclimatization and were excluded from the analysis. The average of the following 15 cycles was taken as the reading for each mouse. Ocular perfusion pressure was expressed as the difference between arterial blood pressure and intraocular pressure (IOP). We calculated systolic, diastolic, and mean ocular perfusion pressure, respectively. After mice ( $n=8$ per genotype) had been killed by $\mathrm{CO}_{2}$ exposure, blood was collected from the heart, and serum total cholesterol was determined using the scil Reflovet ${ }^{\circledR}$ Plus (scil animal care company GmbH, Viernheim, Germany).

2.3. Measurements of Retinal Arteriole Reactivity. Retinal arteriole reactivity was measured in isolated retinas using videomicroscopy as previously described [22, 23]. First, mice ( $n=8$ per genotype) were sacrificed by $\mathrm{CO}_{2}$ exposure, and per mouse one eye was isolated and put into cold Krebs-Henseleit buffer. After preparation of the ophthalmic artery, isolation of the retina, cannulation of the ophthalmic artery, and placing the retina onto a transparent plastic platform, retinal arterioles were pressurized to $50 \mathrm{~mm} \mathrm{Hg}$. First-order retinal arterioles were then imaged under bright-field conditions and their responses measured after 30 minutes of equilibration. Concentration-response curves for the thromboxane mimetic, U46619 $\left(10^{-11}\right.$ to $10^{-6} \mathrm{M}$; Cayman Chemical, Ann Arbor, MI, USA), were conducted. Vessels were then preconstricted to $50-70 \%$ of the initial luminal diameter by titration of U46619 and responses to the endothelium-dependent vasodilator, acetylcholine $\left(10^{-9}\right.$ to $10^{-4} \mathrm{M}$; Sigma-Aldrich, Taufkirchen, Germany), and to the endothelium-independent nitric oxide (NO) donor, sodium nitroprusside (SNP, $10^{-9}$ to $10^{-4} \mathrm{M}$, SigmaAldrich), were measured.

2.4. Quantification of Reactive Oxygen Species. ROS formation was determined in $10 \mu \mathrm{m}$ cryosections of the retina and optic nerve by dihydroethidium- (DHE-, $1 \mu \mathrm{m}$ ) derived fluorescence according to a modified protocol for vascular cryosections ( $n=8$ per genotype) [24]. In retinal sections, the fluorescence $(518 \mathrm{~nm} / 605 \mathrm{~nm}$ excitation/emission) was measured in blood vessels and in individual layers of the inner retina as previously described [25-27].

2.5. Immunfluorescence Analysis. Immunostainings were used to quantify reactive nitrogen species (RNS) in cryopreserved retinal and optic nerve cross-sections $(n=8$ per genotype) stained with an antibody directed against nitrotyrosine (for details see Table 1). Moreover, antibodies directed 
TABLE 1: Specifications of antibodies used for immunofluorescence analysis.

\begin{tabular}{|c|c|c|c|}
\hline Antibody & Article number, company & Species, clonality & Dilution \\
\hline Nitrotyrosine & $\begin{array}{l}\text { 06-284, Merck Millipore, } \\
\text { Darmstadt, Germany }\end{array}$ & Rabbit, polyclonal & $1: 100$ \\
\hline NOX1 & $\begin{array}{l}\text { ab131088, Abcam, Waltham, } \\
\text { MA, USA }\end{array}$ & Rabbit, polyclonal & $1: 200$ \\
\hline NOX2 & $\begin{array}{l}\text { ab129068, Abcam, Waltham, } \\
\text { MA, USA }\end{array}$ & Rabbit, monoclonal & $1: 200$ \\
\hline NOX4 & $\begin{array}{l}\text { ab109225, Abcam, Waltham, } \\
\text { MA, USA }\end{array}$ & Rabbit, monoclonal, & $1: 200$ \\
\hline LOX-1 & $\begin{array}{c}\text { bs-2044R, Biozol Diagnostica } \\
\text { Vertrieb GmbH, Eching, Germany }\end{array}$ & Rabbit, polyclonal & $1: 100$ \\
\hline $\begin{array}{l}\text { FITC-coupled secondary antibody } \\
\text { (for nitrotyrosine staining) }\end{array}$ & $\begin{array}{l}\text { 111-095-003, dianova GmbH, } \\
\text { Hamburg, Germany }\end{array}$ & Goat anti-rabbit, polyclonal & $1: 200$ \\
\hline $\begin{array}{l}\text { Rhodamine red-X-coupled secondary } \\
\text { antibody (for NOX1, NOX, NOX4 } \\
\text { and LOX-1 staining) }\end{array}$ & $\begin{array}{l}\text { 111-295-003, dianova GmbH, } \\
\text { Hamburg, Germany }\end{array}$ & Goat anti-rabbit, polyclonal & $1: 200$ \\
\hline
\end{tabular}

against the isoforms of nicotinamide adenine dinucleotide phosphate oxidase (NOX), NOX1, NOX2, and NOX4, respectively, and against the lectin-like oxidized low-density lipoprotein receptor-1 (LOX-1) were used to quantify the respective proteins in retinal cross-sections of $7 \mu \mathrm{m}$ thickness (for antibody details see Table 1). Fixation of tissue sections for 20 minutes in paraformaldehyde $(4 \%)$ was followed by preincubation with bovine serum albumin (1\%) for 30 minutes and then by the respective primary antibody for 2 hours at room temperature. All primary antibodies displayed pronounced immunoreactivity in the thoracic aorta from ApoE-/- mice (positive control), but not from wild-type mice, at the concentrations used for retinal immunostainings, suggesting that they were suitable to detect the respective gene products. After washing the slides in PBS $(3 \times 5$ $\mathrm{min}$ ), the secondary antibody was applied for 1 hour at room temperature (for details see Table 1). Negative control sections were incubated with a blocking medium and the secondary antibody. Finally, slides were washed in PBS $(3 \times 5$ min) and were mounted using VECTASHIELD ${ }^{\circledR}$ Mounting Medium with DAPI (BIOZOL Diagnostica Vertrieb GmbH, Eching, Germany) and cover-slipped. Subsequently, the fluorescence was measured in blood vessels and in individual layers of the inner retina.

2.6. Real-Time PCR. Messenger RNA for the hypoxic markers, $H I F-1 \alpha$ and $V E G F-A$; the prooxidant redox enzymes, NOX1, NOX2, and NOX; the antioxidant redox enzymes, catalase, GPx1, HO-1, SOD1, SOD2 and SOD3; and for the nitric oxide synthase (NOS) isoforms, eNOS, $i N O S$, and $n N O S$, was quantified in the retina of ApoE-/and wild-type mice ( $n=8$ per genotype) by real-time PCR. After mice had died by $\mathrm{CO}_{2}$ exposure, the one eye per mouse was immediately excised and transferred into cooled phosphate-buffered solution (PBS, Invitrogen, Karlsruhe, Germany) to isolate the retina under a dissecting microscope. Next, the isolated retina was transferred into $1.5 \mathrm{ml}$ plastic tube, rapidly frozen in liquid nitrogen, and stored at $-80^{\circ} \mathrm{C}$. Later, tissue samples were homogenized (FastPrep; MP Bio- medicals, Illkirch, France), and the expression of genes was measured by SYBR Green-based quantitative real-time PCR, as previously described [28]. RNA was isolated using peqGOLD TriFast ${ }^{\mathrm{TM}}$ (PEQLAB) and cDNA was generated with the High-Capacity cDNA Reverse Transcription Kit (Applied Biosystems, Darmstadt, Germany). Real-time PCR reactions were performed on a StepOnePlus ${ }^{\mathrm{TM}}$ Real-Time PCR System (Applied Biosystems) using SYBR ${ }^{\circledR}$ Green JumpStart $^{\mathrm{TM}}$ Taq ReadyMix ${ }^{\mathrm{TM}}$ (Sigma-Aldrich) and $20 \mathrm{ng}$ cDNA. Relative mRNA levels of target genes were quantified using comparative threshold (CT) normalized to housekeeping gene TATA-binding protein (TBP). Messenger RNA expression is presented as the fold-change in ApoE-/- mice versus wild-type mice. The PCR primer sequences are listed in Table 2.

2.7. Cell Counting in Retinal Wholemounts. Post mortem, one eye per mouse ( $n=8$ per genotype) was excised and fixed in $4 \%$ paraformaldehyde (Sigma-Aldrich) for 30 minutes. Next, a retinal wholemount was prepared in cold PBS, transferred onto a glass slide, and stained with cresyl blue as previously described [29]. After the staining procedure, sixteen predefined areas per wholemount, eight central and eight peripheral, of $150 \mu \mathrm{m} \times 200 \mu \mathrm{m}$ were photographed by a blinded investigator as reported in detail previously [25, 30, 31]. Per photograph, all cresyl blue-positive cells were counted manually by a blinded investigator using the cell counter plugin for ImageJ software (NIH, http://rsb.info.nih.gov/ij/) as previously described $[25,31]$. The mean cell density (cells $/ \mathrm{mm}^{2}$ ) was calculated and multiplied with the wholemounts' surface area to obtain the total number of cells per retina.

2.8. Axon Counting in Optic Nerve Cross-Sections. Per mouse, one optic nerve was isolated ( $n=8$ per genotype), placed in fixative solution, and embedded in agar 100 resin. Afterwards, semithin cross-sections were cut with an ultramicrotome (Ultracut E, Leica, Bensheim, Germany), placed on glass slides, and stained with $1 \%$ toluidine blue in $1 \%$ sodium borate according to standard protocols. Each cross-section 
TABLE 2: Sequences of the primers used for real-time PCR analysis.

\begin{tabular}{|c|c|c|}
\hline Gene & Forward & Reverse \\
\hline$H I F-1 \alpha$ & TCATCAGTTGCCACTTCCCCAC & CCGTCATCTGTTAGCACCATCAC \\
\hline$V E G F-A$ & ACTTGTGTTGGGAGGAGGATGTC & AATGGGTTTGTCGTGTTTCTGG \\
\hline NOX1 & GGAGGAATTAGGCAAAATGGATT & GCTGCATGACCAGCAATGTT \\
\hline NOX2 & CCAACTGGGATAACGAGTTCA & GAGAGTTTCAGCCAAGGCTTC \\
\hline NOX4 & TGTAACAGAGGGAAAACAGTTGGA & GTTCCGGTTACTCAAACTATGAAGAGT \\
\hline eNOS & CCTTCCGCTACCAGCCAGA & CAGAGATCTTCACTGCATTGGCTA \\
\hline iNOS & CAGCTGGGCTGTACAAACCTT & CATTGGAAGTGAAGCGTTTCG \\
\hline$n N O S$ & TCCACCTGCCTCGAAACC & TTGTCGCTGTTGCCAAAAAC \\
\hline Catalase & CAAGTACAACGCTGAGAAGCCTAAG & CCCTTCGCAGCCATGTG \\
\hline$G P x 1$ & CCCGTGCGCAGGTACAG & GGGACAGCAGGGTTTCTATGTC \\
\hline $\mathrm{HO}-1$ & GGTGATGCTGACAGAGGAACAC & TAGCAGGCCTCTGACGAAGTG \\
\hline SOD1 & CCAGTGCAGGACCTCATTTTAAT & TCTCCAACATGCСТCTCTTCATC \\
\hline SOD2 & СCTGCTCTAATCAGGACCCATT & CGTGCTCCCACACGTCAAT \\
\hline SOD3 & TTCTTGTTCTACGGCTTGCTACTG & AGCTGGACTCCCCTGGATTT \\
\hline TBP & CTT CGT GCA AGA AAT GCT GAA T & CAG TTG TCC GTG GCT CTC TTA TT \\
\hline
\end{tabular}

TABLE 3: Intraocular pressure, blood pressure, ocular perfusion pressure, and total serum cholesterol in wild-type and ApoE-/- mice $(n=8$ per genotype).

\begin{tabular}{lccc}
\hline Systemic parameters & Wild type & ApoE-/- & $P$ value \\
\hline Intraocular pressure (mm hg) & $11.95 \pm 0.5491$ & $11.56 \pm 0.6165$ & \\
Blood pressure (mm hg) & & & \\
Systolic & $98.68 \pm 4.341$ & $105.7 \pm 4.263$ & 0.6428 \\
Diastolic & $67.74 \pm 3.959$ & $63.23 \pm 4.606$ & 0.2701 \\
Mean & $77.73 \pm 3.907$ & $77.06 \pm 3.941$ & 0.9051 \\
Ocular perfusion pressure (mm hg) & & $94.12 \pm 3.925$ \\
Systolic & $86.73 \pm 4.024$ & $51.68 \pm 4.390$ & 0.2098 \\
Diastolic & $55.79 \pm 3.631$ & $65.50 \pm 3.647$ & 0.4817 \\
Mean & $65.79 \pm 3.568$ & $511.0 \pm 12.21$ & 0.9566 \\
Total cholesterol (mg/dL) & $145.1 \pm 5.642$ & $<\mathbf{0 . 0 0 0 1}$ \\
\hline
\end{tabular}

was examined using bright-field microscopy by a blinded investigator. Five nonoverlapping fields of $60 \mu \mathrm{m} \times 80 \mu \mathrm{m}$ (one central and four peripheral) were photographed per cross-section. Axons were counted manually by a blinded investigator using ImageJ software. The mean axon density (axons $/ \mathrm{mm}^{2}$ ) was calculated and multiplied by the crosssectional area to obtain the total number of axons per optic nerve as described recently in detail $[25,31]$.

2.9. Statistical Analysis. Data are presented as mean \pm SE, and $n$ represents the number of mice per group. Constriction responses to U46619 are presented as percent change in luminal diameter from resting diameter, while responses to SNP and acetylcholine are presented as percent change in luminal diameter from the preconstricted diameter. Comparison between concentration-responses was made using twoway ANOVA for repeated measurements. For comparisons of IOP, blood pressure, ocular perfusion pressure, total serum cholesterol, fluorescent intensity, mRNA expression levels, and cell and axon numbers, an unpaired $t$-test was used. The level of significance was set at 0.05 .

\section{Results}

3.1. Intraocular Pressure, Blood Pressure, Ocular Perfusion Pressure, and Total Serum Cholesterol. No differences in intraocular pressure, blood pressure, and ocular perfusion pressure were detected between ApoE-/- and wild-type mice. Total serum cholesterol was markedly elevated in ApoE-/mice compared to wild-type mice $(P<0.0001, n=8$ per genotype). The data are presented in Table 3.

3.2. Responses of Retinal Arterioles. The initial luminal diameter of retinal arterioles was similar in both mouse genotypes $(20.52 \pm 0.9656 \mu \mathrm{m}$ and $21.58 \pm 0.9808 \mu \mathrm{m}$ in ApoE- $/-$ and wild-type mice, respectively, $P=0.4550, n=8$ per genotype). 


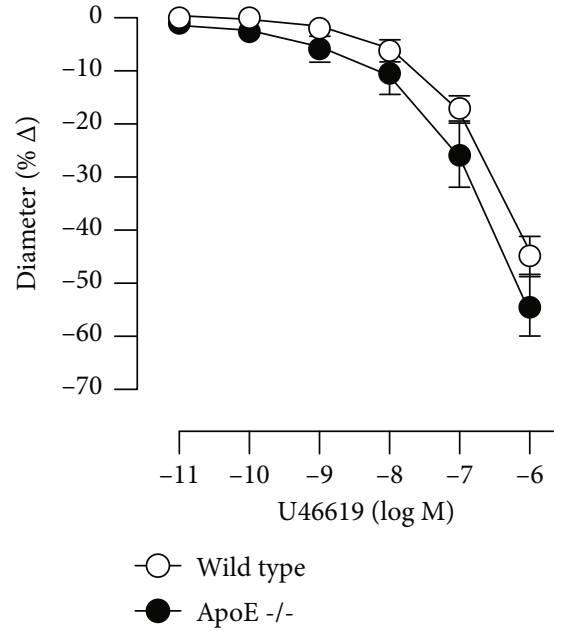

(a)

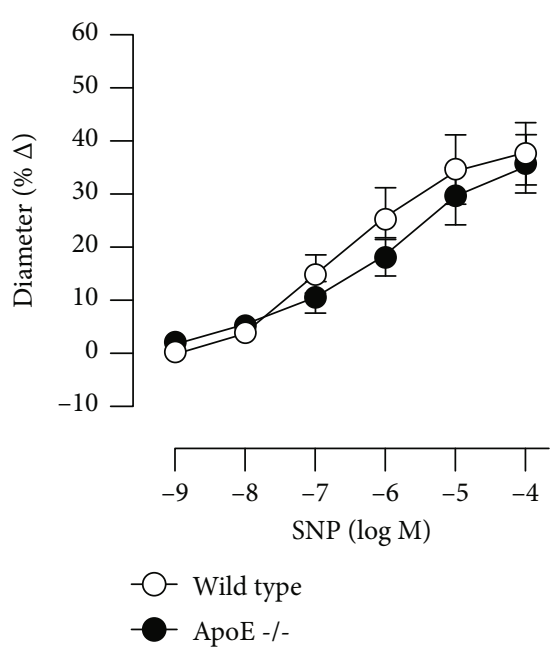

(b)

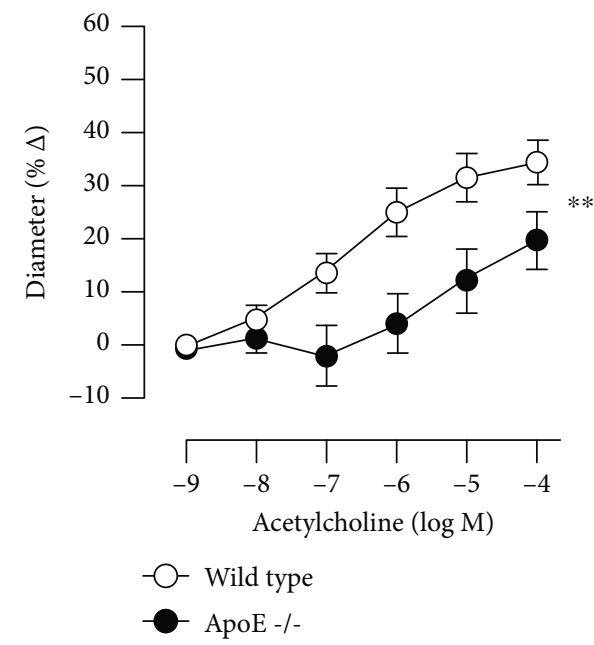

(c)

Figure 1: Responses of retinal arterioles from ApoE-/- and wild-type mice to the thromboxane mimetic, U46619 (a), the endotheliumindependent vasodilator, SNP (b), and to the endothelium-dependent vasodilator, acetylcholine (c). Values are presented as mean \pm SE $\left(n=8\right.$ per concentration and genotype; $\left.{ }^{* *} P<0.01\right)$.

U46619 elicited concentration-dependent vasoconstriction of retinal arterioles that was similar in ApoE-/- and wildtype mice $(54.50 \pm 5.441 \%$ versus $44.86 \pm 3.495 \%$, ApoE-/versus wild-type mice at $10^{-6} \mathrm{M} ; P>0.05$; Figure $1(\mathrm{a})$ ). The endothelium-independent vasodilator, SNP, elicited concentration-dependent vasodilation that did also not differ between both mouse genotypes $(35.77 \pm 5.531 \%$ versus $37.70 \pm 5.837 \%$, ApoE-/- versus wild-type mice at $10^{-4} \mathrm{M}$; $P>0.05$; Figure $1(\mathrm{~b}))$. In contrast, the endotheliumdependent vasodilator, acetylcholine, produced concentrationdependent vasodilation, which was impaired in arterioles from ApoE-/- mice $(19.79 \pm 5.576 \%$ versus $34.41 \pm 4.175 \%$, ApoE-/- versus wild-type mice at $10^{-4} \mathrm{M} ; \quad P<0.01$; Figure 1(c)).

3.3. ROS and RNS Formation in the Retina and Optic Nerve. Staining of retinal sections with DHE revealed increased fluorescence intensity specifically in retinal blood vessels from ApoE-/- mice, indicative of elevated ROS levels $(P=0.0022$, ApoE-/- versus wild-type mice, $n=8$ per genotype; Figures 2(a), 2(b), and 2(e)). No differences in fluorescence intensity where found between both genotypes in the individual layers of the inner retina ( $n=8$ per genotype; Figures 2(a), 2(b), and 2(e)). Similarly, in cross-sections of the optic nerve, no differences in DHE fluorescence intensity were found between wild-type and ApoE- - mice $(n=8$ per genotype; Figures 2(c)-2(e)). Immunoreactivity to nitrotyrosine was negligible in blood vessels and in all inner retinal layers of both mouse genotypes $(n=8$ per genotype; Figures 3(a), 3(b), 3(d) and 3(e)), suggesting that RNS levels were very low and not increased in ApoE-/- mice (Figure 3(g)). In optic nerve cross-sections of both genotypes, some green hyperfluorescent spots were visible (Figures 3(c) and 3(f)), but no differences in immunoreactivity to nitrotyrosine were detectable between wild-type and ApoE-/- mice $(n=8$ per genotype; Figure $3(\mathrm{~g}))$. 
WT, retina, DHE

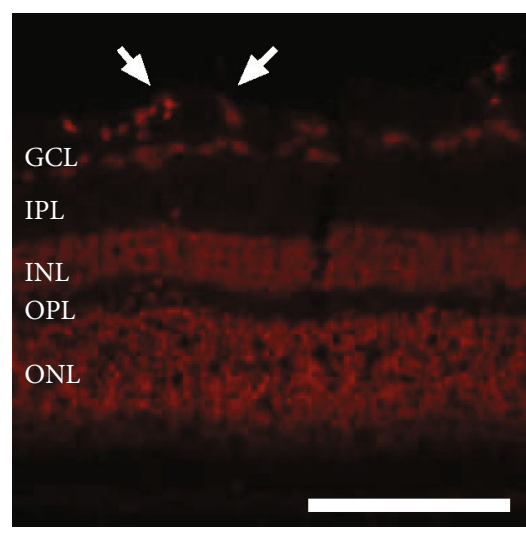

(a)

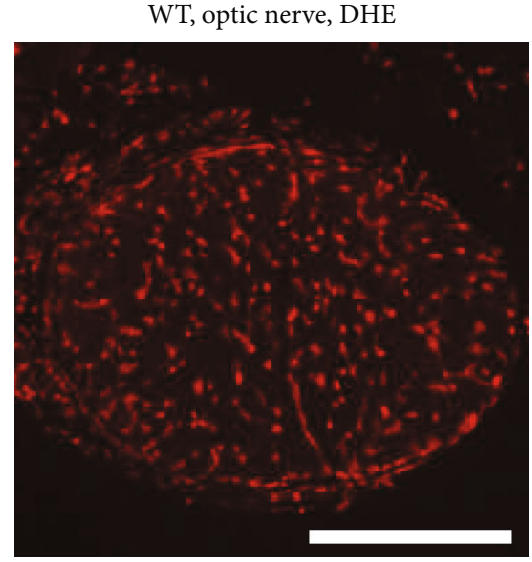

(c)
ApoE-/-, retina, DHE

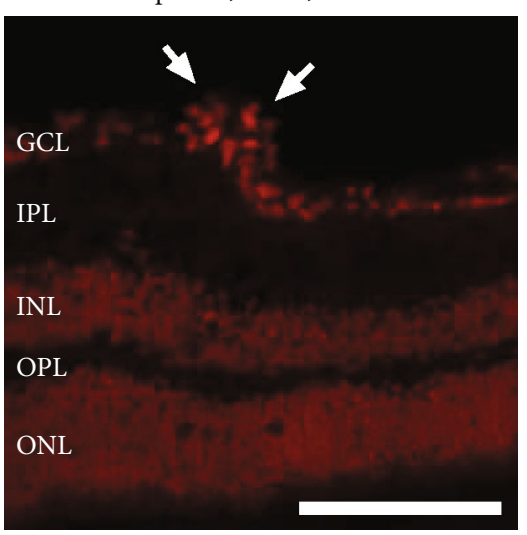

(b)

ApoE-/-, optic nerve, DHE

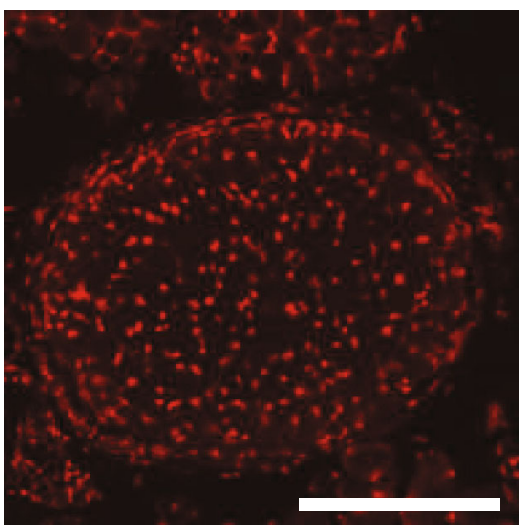

(d)

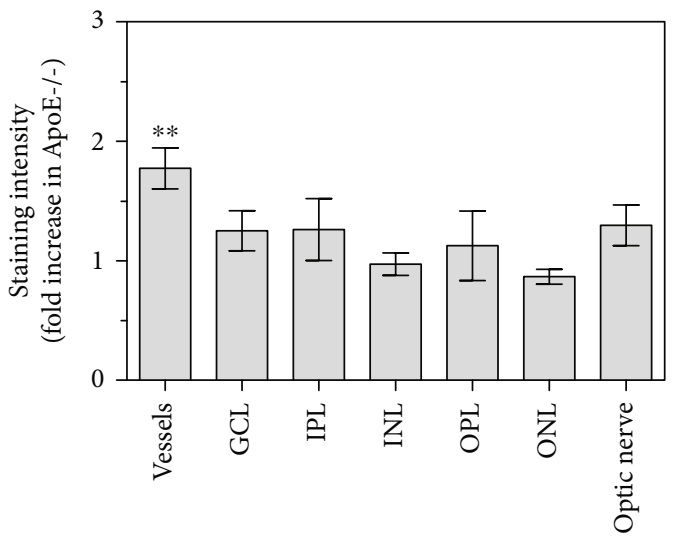

(e)

Figure 2: DHE stainings of retinal cross-sections ( $a, b)$ and of optic nerve cross-sections (c, d) from wild-type and ApoE-/- mice, respectively. Staining intensity was increased in retinal blood vessels from ApoE-/- mice but did neither differ in any of the retinal layers nor in the optic nerve between both genotypes (e). The white arrows point to retinal blood vessel cross-sections. GCL: ganglion cell layer; IPL: inner plexiform layer; INL: inner nuclear layer; OPL: outer plexiform layer; ONL: outer nuclear layer. Values are presented as mean \pm SE $(n=8$ per genotype; $\left.{ }^{* *} P<0.01\right)$. Scale bar $=100 \mu \mathrm{m}$.

3.4. NOX1, NOX2, and NOX4 Expressions in the Retina. Immunoreactivity to NOX1 did not differ between blood vessels and any of the inner retinal layers of ApoE-/- and wild-type mice ( $n=8$ per genotype; Figures $4(\mathrm{a})-4(\mathrm{~g})$ ). In contrast, immunoreactivity to NOX2 was markedly increased in retinal blood vessels from ApoE-/- mice
( $P=0.0027$, ApoE-/- versus wild-type mice, $n=8$ per genotype), but did not differ in individual retinal layers of both mouse genotypes (Figures 4(h)-4(n)). NOX4 immunoreactivity was similar in blood vessels and all retinal layers of both mouse genotypes ( $n=8$ per genotype; Figures 4(o)-4(u)). 


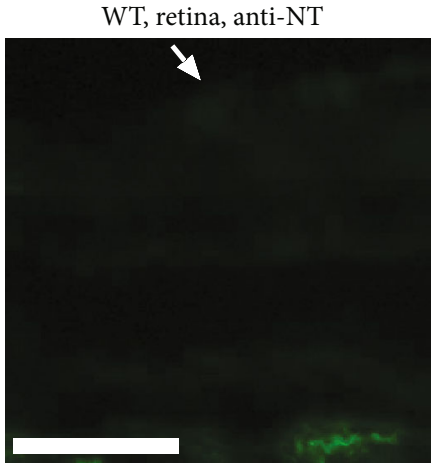

(a)

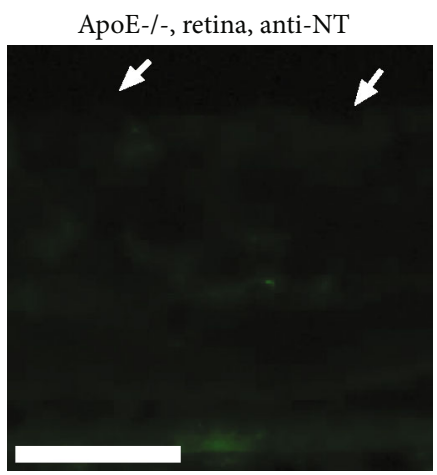

(d)
$\mathrm{WT}$, retina, anti-NT + DAPI

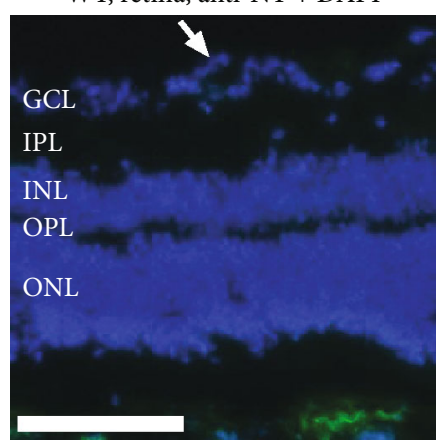

(b)

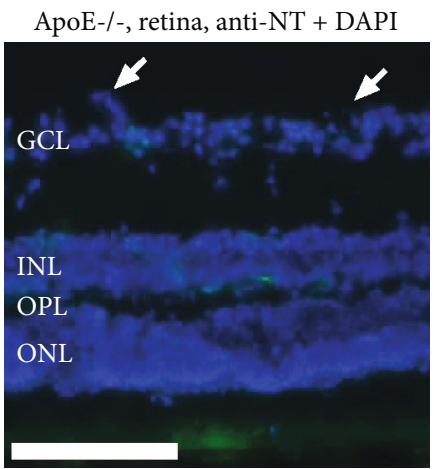

(e)

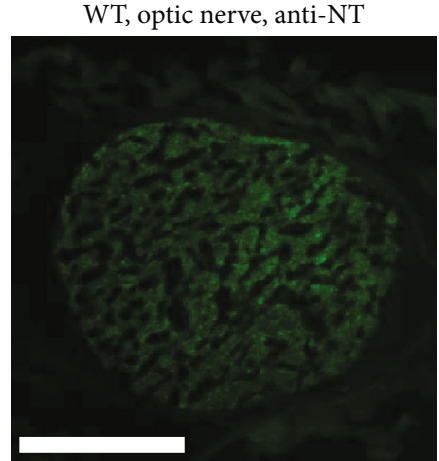

(c)

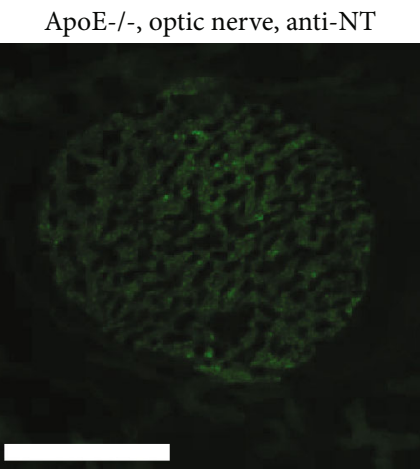

(f)

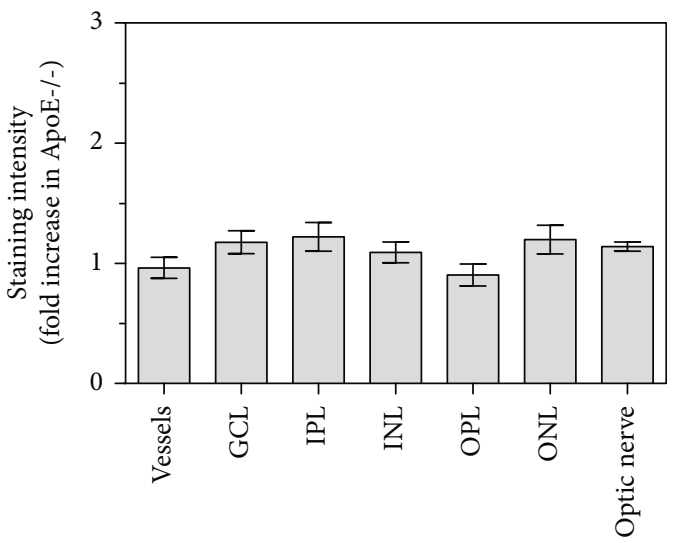

(g)

FIGURE 3: Nitrotyrosine immunostainings (anti-NT) in retinal cross-sections and optic nerve cross-sections from wild-type (a-c) and ApoE-/- mice (d-f). Immunoreactivity to nitrotyrosine was negligible in the inner retina of both genotypes (a, d). In optic nerve cross-sections, some green hyperfluorescent spots were visible, but no differences in fluorescent intensity were observed between both genotypes (g). The white arrows point to retinal blood vessels cross-sections. GCL: ganglion cell layer; IPL: inner plexiform layer; INL: inner nuclear layer; OPL: outer plexiform layer; ONL: outer nuclear layer. Values are presented as mean \pm SE ( $n=8$ per genotype). Scale $\operatorname{bar}=100 \mu \mathrm{m}$.

3.5. Expression of LOX-1 in the Retina. Immunoreactivity to LOX-1, which serves as a receptor for ox-LDL, was faint in the inner retina of wild-type mice. Also, immunoreactivity in blood vessels was not pronounced in retinas of wild-type mice $(n=8$ per genotype; Figures $5(\mathrm{a})-5(\mathrm{c}))$. The immunoreactivity pattern in individual retinal layers from ApoE-/mice resembled the one from wild-type mice. However, strong immunoreactivity was seen in retinal blood vessels from ApoE-/- mice ( $n=8$ per genotype; Figures 5(c)-5(e)). The staining intensity was markedly stronger in retinal blood vessels from ApoE-/- mice compared to wild-type mice $(P=0.0007, n=8$ per genotype; Figure 5(f)).

3.6. Expression of Hypoxic and Redox Genes in the Retina. In the retina of ApoE-/- mice, mRNA for both hypoxic markers, $H I F-1 \alpha$ and $V E G F-A$, was slightly but significantly elevated compared to wild-type mice (1.7-fold for $H I F-1 \alpha, P=$ 0.0013 and 1.4 -fold for $V E G F-A, P=0.0095, n=8$ per genotype), indicative of a hypoxic condition (Figure 6(a)). Also, mRNA for the prooxidant redox genes, NOX1 and NOX2, 
WT, retina, anti-NOX1

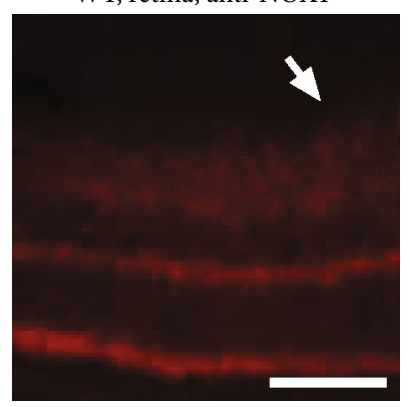

(a)

ApoE-/-, retina, anti-NOX1

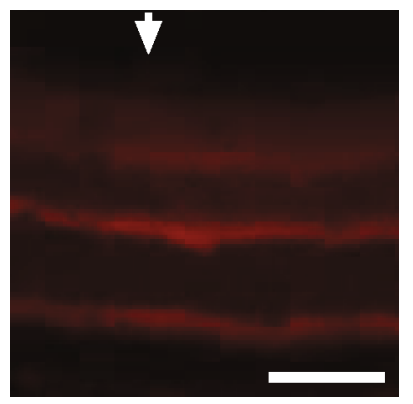

(d)
WT, retina, DAPI

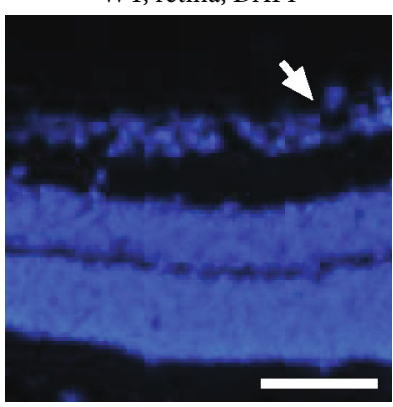

(b)

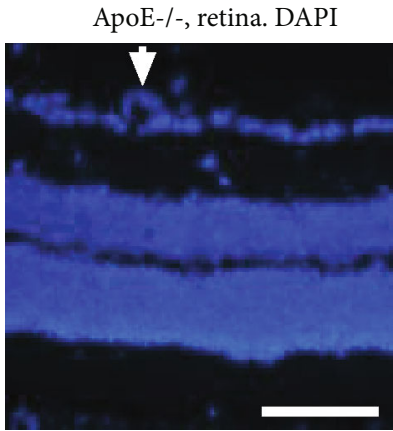

(e)

NOX1 expression

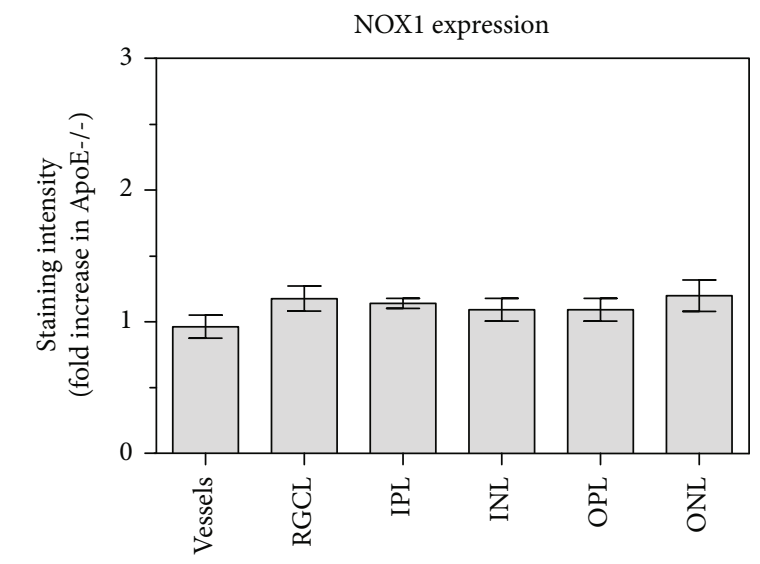

(g)

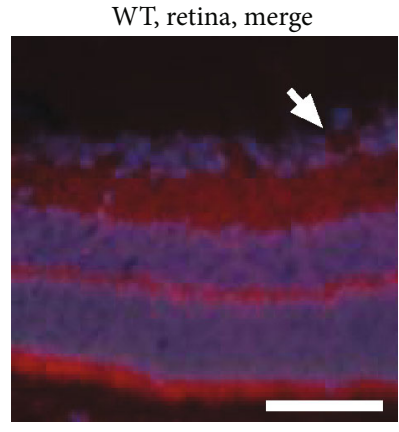

(c)

ApoE-/-, retina, merge

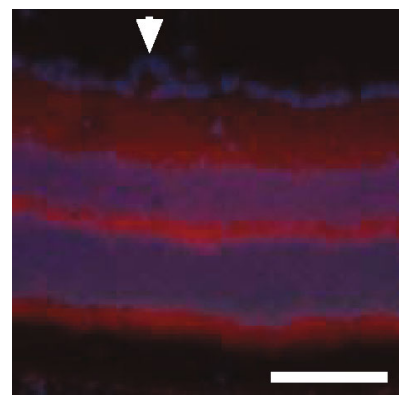

(f)

WT, retina, anti-NOX2

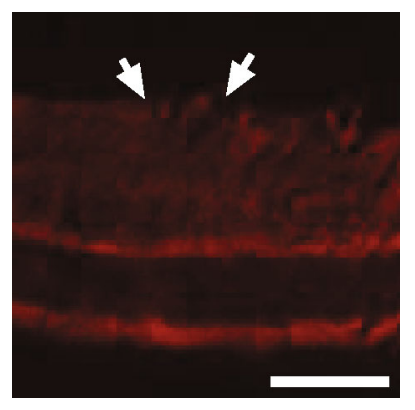

(h)
WT, retina,DAPI

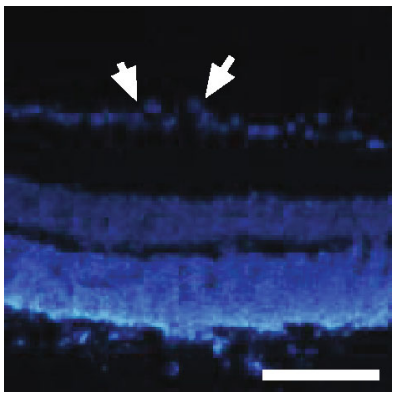

(i)

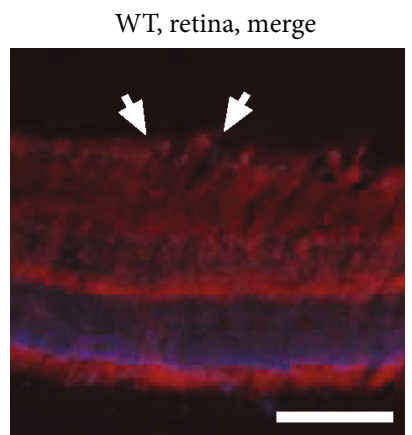

(j)

Figure 4: Continued. 


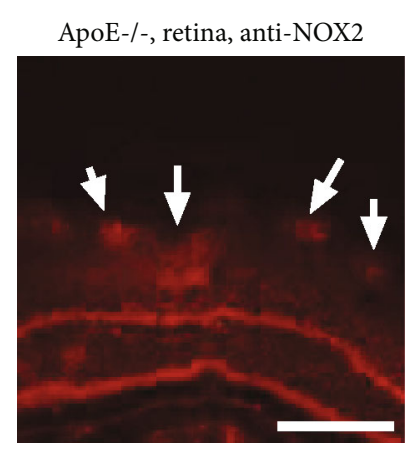

(k)

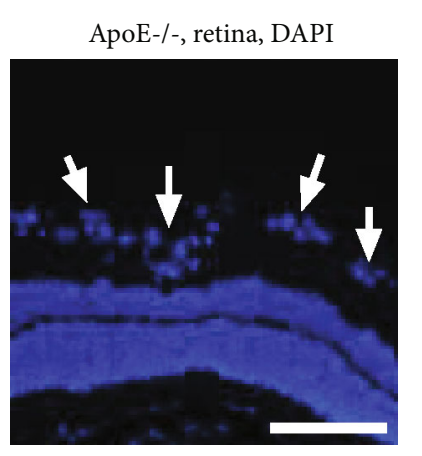

(l)

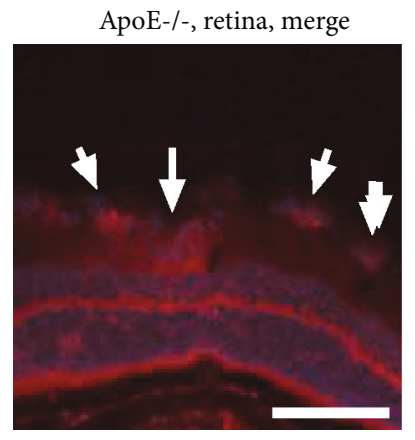

(m)

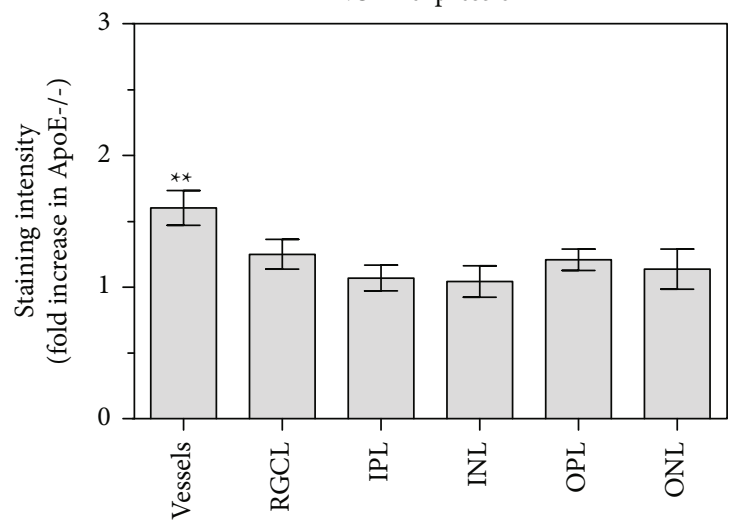

(n)

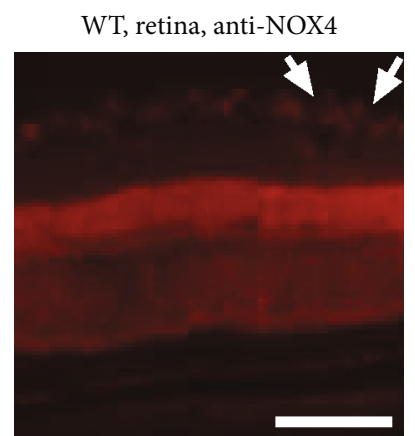

(o)

ApoE-/-, retina, anti-NOX4

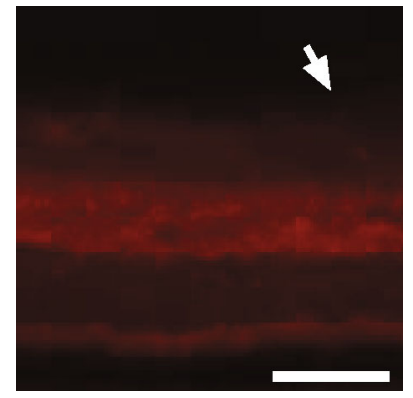

(r)

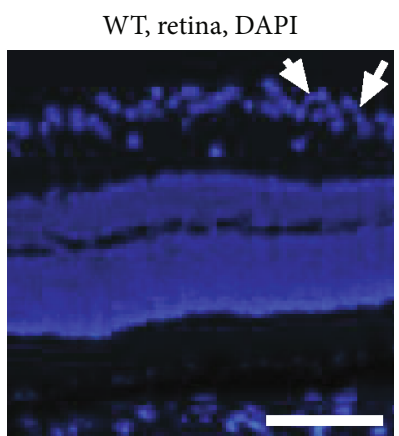

(p)

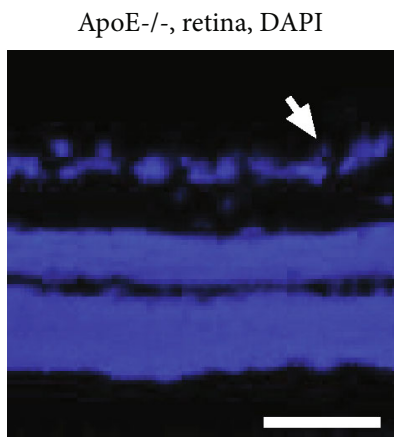

(s)

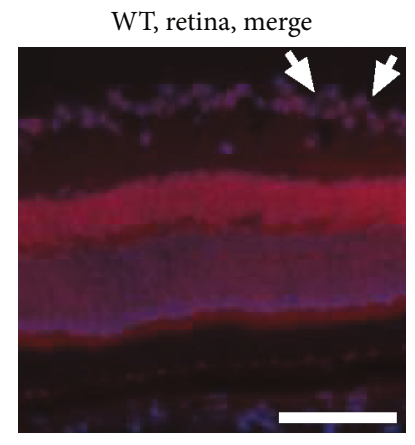

(q)

ApoE-/-, retina, merge

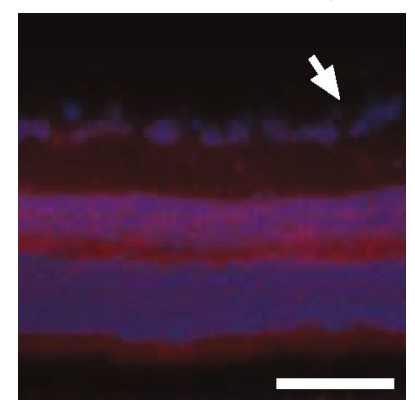

$(\mathrm{t})$

Figure 4: Continued. 


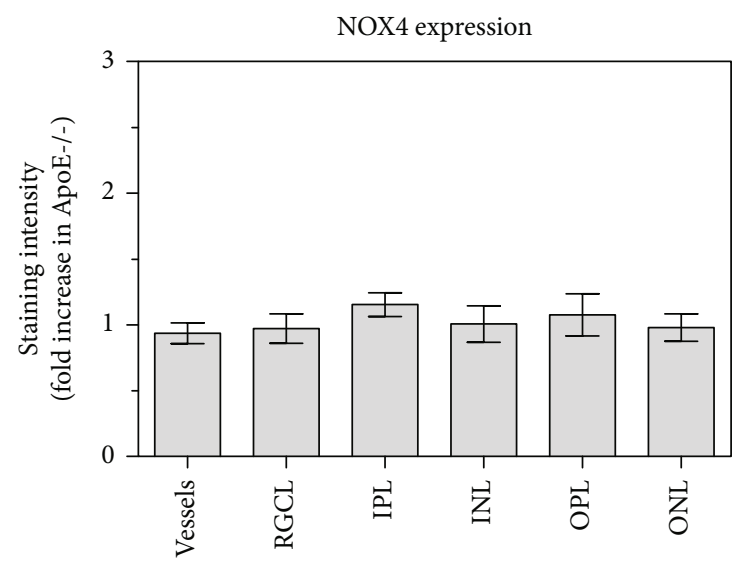

$(\mathrm{u})$

Figure 4: Immunostainings for NOX1 (a-g), NOX2 (h-n), and NOX4 (o-u) in retinal cross-sections from wild-type and ApoE-/- mice. Immunoreactivity to NOX1 was similar in blood vessels and all retinal layers in both mouse genotypes (g). In contrast, immunoreactivity to NOX2 was increased in retinal blood vessels from ApoE-/- mice but did not differ in individual retinal layers of both mouse groups (n). Immunoreactivity to NOX4 was also similar throughout the retina in both genotypes $(\mathrm{u})$. The white arrows point to retinal blood vessel cross-sections. GCL: ganglion cell layer; IPL: inner plexiform layer; INL: inner nuclear layer; OPL: outer plexiform layer; ONL: outer nuclear layer. Values are presented as mean \pm SE $\left(n=8\right.$ per genotype; $\left.{ }^{* *} P<0.01\right)$. Scale bar $=100 \mu \mathrm{m}$.

was increased in the retina from ApoE-/- mice compared to wild-type mice (2.0-fold for NOX1, $P=0.0053$ and 2.1 -fold for NOX2, $P=0.0312, n=8$ per genotype; Figure 6(b)). Among the three nitric oxide synthase (NOS) isoforms, mRNA expression for inducible (iNOS) and neuronal NOS ( $n N O S)$ was found to be increased (1.3-fold for iNOS, $P=$ 0.0009 and 2.6-fold for $n N O S, P=<0.0001, n=8$ per genotype; Figure $6(\mathrm{c})$ ). Interestingly, also mRNA expression for all antioxidant redox genes tested was elevated (5.2-fold for catalase, $P<0.0001 ; 1.4$-fold for $G P x-1, P=0.0063 ; 2.0$-fold for $H O-1, P=0.0005 ; 1.3$-fold for SOD $1, P=0.0180 ; 1.4$-fold for SOD2, $P=0.0383$; 3.1-fold for SOD3, $P=0.0006, n=8$ per genotype; Figure 6(d)).

3.7. Retinal Ganglion Cell Layer Cells and Optic Nerve Axons. Total cell number in the RGC layer was $108063 \pm 2745$ and $102255 \pm 3558$ in ApoE-/- and wild-type mice and did not differ between both genotypes $(P=0.2171, n=8$ per genotype; Figure 7). The number of axons in the optic nerve, representing the axons of RGCs, did also not differ between both genotypes. The axon number was $46790 \pm 1493$ and $45554 \pm 2145$ in ApoE-/- and wild-type mice, respectively, and was not different between both mouse genotypes $(P=0.6435, n=8$ per genotype; Figure 7$)$.

\section{Discussion}

There are several major new findings emerging from this experimental study. First, the lack of apolipoprotein E had no effect on intraocular pressure, blood pressure, and ocular perfusion pressure but affected reactivity of retinal arterioles to the endothelium-dependent vasodilator, acetylcholine, indicative of endothelial dysfunction. Second, ROS levels, but not RNS levels, were found to be elevated in retinal arterioles of ApoE-/- mice. In contrast, neither ROS nor RNS were increased in individual retinal layers and the optic nerve of ApoE-/- mice suggesting that oxidative stress is limited to the vasculature and nitrosative stress is negligible. Also, immunoreactivity to LOX-1 and NOX2, but not to NOX1 or NOX4 was elevated in retinal vessels of ApoE-/- mice, suggesting that a mechanism involving LOX-1, NOX2, and ROS may be involved in mediating endothelial dysfunction. The lack of apolipoprotein $\mathrm{E}$ was associated with increased retinal mRNA expression for the hypoxia markers, HIF- $1 \alpha$ and $V E G F-A$, as well as of redox genes coding for the prooxidant enzymes NOX1 and NOX2. However, mRNA expression for the antioxidant redox genes SOD1, SOD3, SOD3, GPx1, $H O-1$, and catalase were also increased, suggesting that enhanced ROS production is associated with a compensation by antioxidant enzymes. Third, total cell number in the RGC layer and axon number in the optic nerve was not affected by the lack of apolipoprotein E. These findings illustrate that apolipoprotein E deficiency causes oxidative stress and endothelial dysfunction in retinal arterioles, but no oxidative damage in nonvascular retinal tissue probably by effective buffering of excessive ROS and RNS generation by antioxidant redox enzymes.

During hypercholesterolemia, oxidized low-density lipoproteins (ox-LDLs) have been shown to trigger the expression of prooxidant enzymes and thus, ROS generation, in the vascular wall via involvement of LOX-1 [32]. Of note, the expression LOX-1, which serves as a receptor for oxLDL, was reported to be upregulated in hypercholesterolemia via positive feedback mechanisms involving the transcription factor NF- $\kappa \mathrm{B}[33,34]$. In agreement with these studies, we found increased LOX-1 expression and increased ROS levels in the vascular wall of retinal blood vessels from ApoE-/mice. In many vascular beds, high ROS concentrations elicit endothelial dysfunction, reflected by a reduced endotheliumdependent vasodilation, in part by affecting eNOS bioactivity and by inactivation of nitric oxide $[32,35,36]$. These mechanisms have also been described in cerebral blood vessels of 
WT, retina, anti-LOX-1

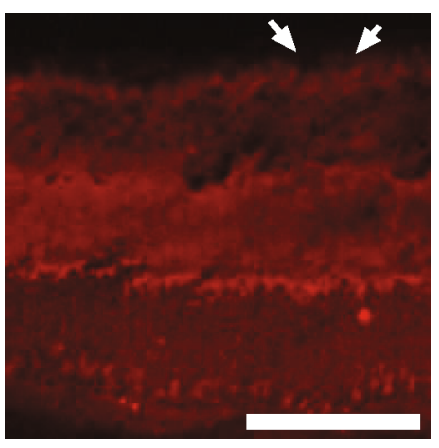

(a)

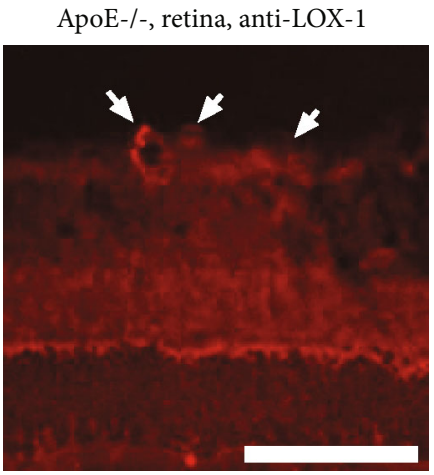

(d)

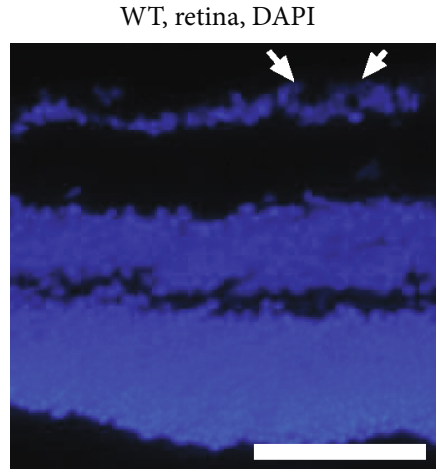

(b)

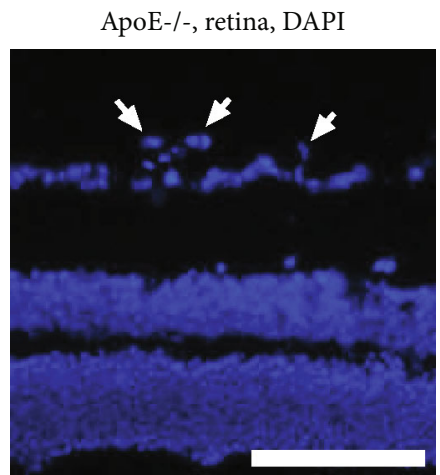

(e)

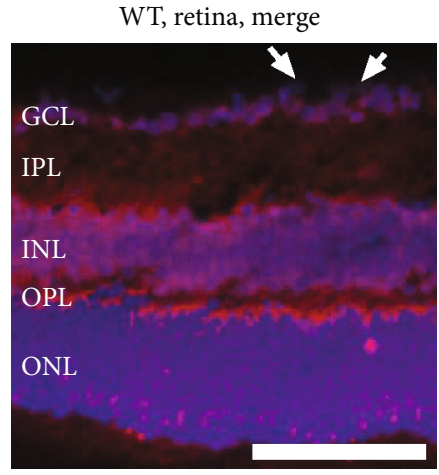

(c)

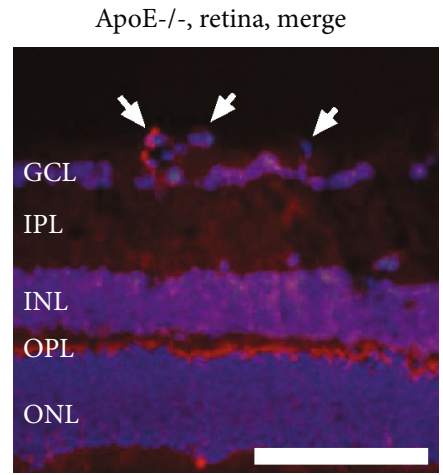

(f)

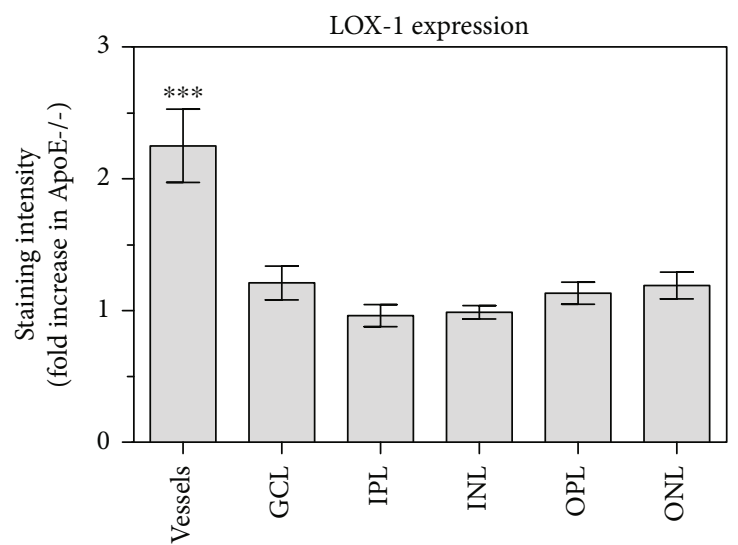

(g)

Figure 5: Immunostainings for the ox-LDL receptor, LOX-1, in retinal cross-sections from wild-type (a-c) and ApoE-/- mice (d-f), respectively. Staining intensity was increased in blood vessels from ApoE-/- mice ( $\mathrm{g}$ ) but did not differ in any of the retinal layers between both genotypes. GCL: ganglion cell layer; IPL: inner plexiform layer; INL: inner nuclear layer; OPL: outer plexiform layer; ONL: outer nuclear layer. Values are presented as mean \pm SE $\left(n=8\right.$ per genotype; $\left.{ }^{* * *} P<0.001\right)$. Scale bar $=100 \mu \mathrm{m}$.

various hypercholesterolemic animal models, including ApoE-/- mice [37-40]. Likewise, in the human retina, elevated serum cholesterol levels have been associated with reduced retinal vascular hyperemic responses to flicker light stimulation, which are in part nitric oxide synthasedependent $[6,7]$. However, the molecular effects of hypercholesterolemia on retinal endothelial function have not been elucidated so far. The findings of the present study suggest that LOX-1, NOX2, and ROS are involved in mediating hypercholesterolemia-induced endothelial dysfunction in the retina, which is in concert with a study in cerebral blood vessels reporting that NOX2-derived ROS abrogated nitric oxide function in ApoE-/- mice [40].

We excluded the possibility that endothelial dysfunction was triggered by differences in IOP, blood pressure, or ocular perfusion pressure between ApoE-/- and wild-type mice. Arterial hypertension is a trigger factor of endothelial dysfunction in various blood vessels, including ocular and cerebral vessels [41, 42]. Conversely, low ocular perfusion pressure was associated with glaucoma prevalence, incidence, and progression [43]. Similar to the present findings, most of the previous studies reported that blood pressure does not 


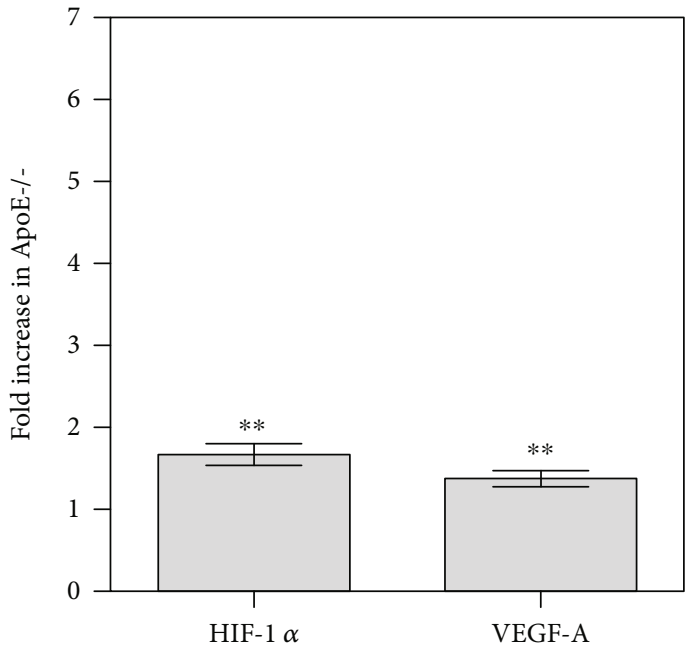

(a)

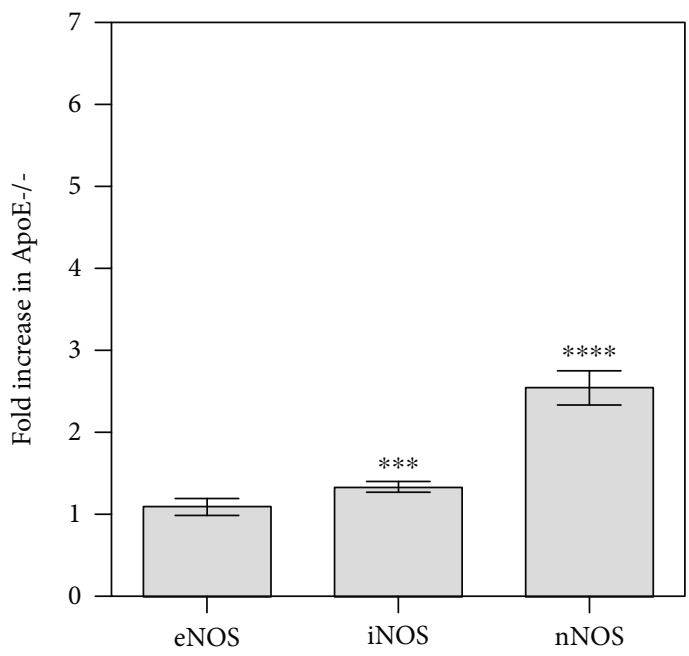

(c)

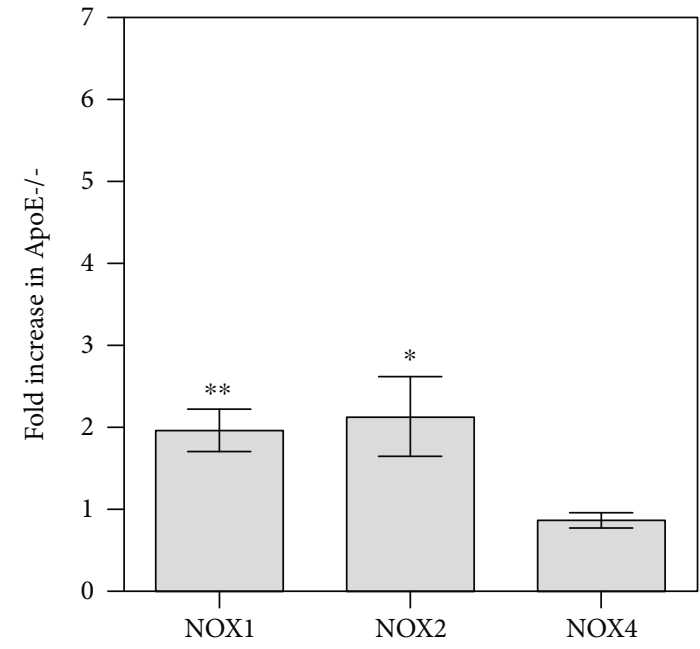

(b)

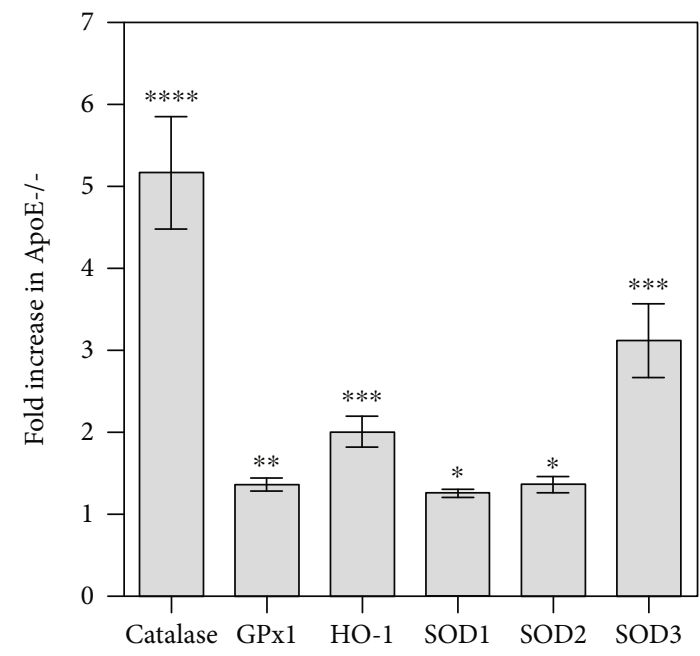

(d)

FIGURE 6: Messenger RNA expression of hypoxic markers ((a) HIF-1 $\alpha$, VEGF-A), prooxidant ((b) NOX1, NOX2, and NOX4), the three nitric oxide synthase isoforms ((c) eNOS, iNOS, and nNOS), and of the antioxidant redox enzymes ((d) catalase, GPx1, HO-1, SOD1, SOD2, and SOD3) in retinal samples from wild-type and ApoE-/- mice. Data are presented as the fold-change (mean \pm SE) in ApoE-/- versus wild-type mice $\left(n=8\right.$ per genotype, $\left.{ }^{*} P<0.05,{ }^{* *} P<0.01,{ }^{* * *} P<0.001,{ }^{* * * *} P<0.0001\right)$.

differ in ApoE-/- and wild-type mice and is stable with age [20, 44-46]. Interestingly, other previous studies in ApoE-/mice revealed that some small blood vessels do not develop endothelial dysfunction $[47,48]$. One possible explanation for these findings is that endothelium-derived hyperpolarizing factor- (EDHF-) dependent vasodilation mechanisms are less affected by hypercholesterolemia [47]. In mouse retinal arterioles, however, endothelium-dependent vasodilation is mainly mediated by eNOS and, during eNOS deficiency, by nNOS and COX-2 metabolites, suggesting that EDHF pathways play only a negligible role $[49,50]$.

An intriguing question concerning many retinal diseases is how endothelial dysfunction affects neuron survival. So far only indirect links between impaired vascular responses and the onset and progression retinal pathologies exist. For example, reduced responses of retinal arterioles to various stimuli have been reported in patients with diabetic retinopathy and glaucoma $[51,52]$. Other studies in humans suggest that certain polymorphisms of the gene coding for eNOS, which plays a major role in endothelial function of retinal arterioles, have a risk association for onset or progression of diabetic retinopathy and of some forms of glaucoma [53-57]. However, in animal models characterized by reduced responsiveness to the endotheliumdependent vasodilator, acetylcholine, such as eNOS-deficient and $\mathrm{M}_{3}$ receptor-deficient mice, no loss of RGCs has been detected $[22,25,30,50]$. On the other hand, in diabetic mice, eNOS deficiency was reported to promote the progression of diabetic retinopathy, suggesting that endothelial dysfunction might accelerate pathophysiological processes in the retina [58].

The retinal vasculature supplies the inner retinal layers, while the outer layers are supplied by choroidal blood vessels [59]. Hence, impaired blood supply due to abnormal 
Wild type

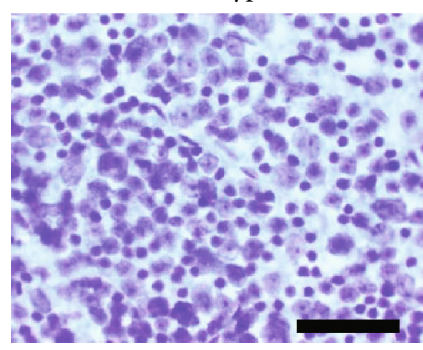

(a)

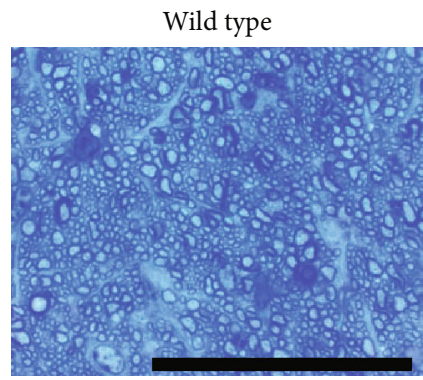

(c)

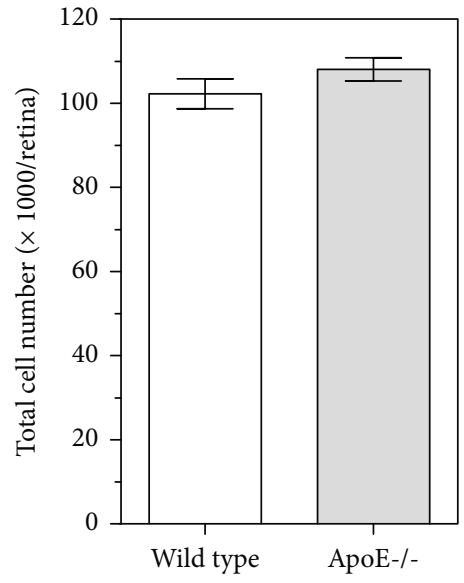

(e)
ApoE -/-

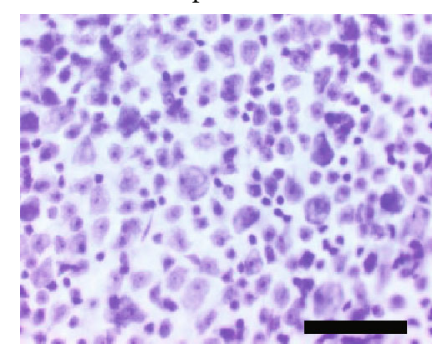

(b)

ApoE -/-

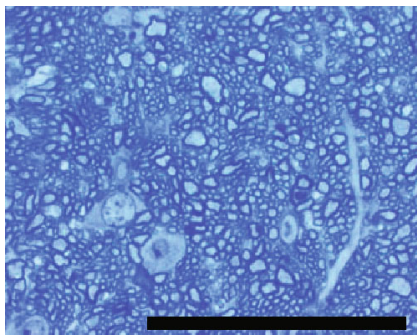

(d)

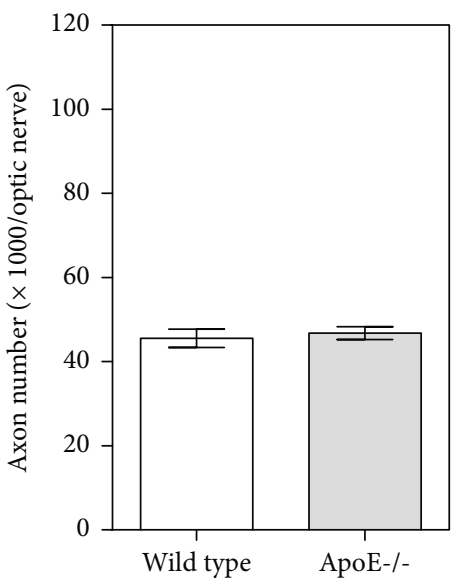

(f)

Figure 7: Example photographs taken from retinal wholemounts stained with cresyl blue and optic nerve cross-sections stained with toluidine blue of wild-type (a, c) and ApoE-/- mice (b, d). Total cell number in the RGC layer (e) and axon number (f) in the optic nerve was similar in wild-type and ApoE-/- mice. Values are presented as mean \pm SE ( $n=8$ per genotype). Scale bar $=50 \mu \mathrm{m}$.

reactivity of retinal vessels is supposed to affect primarily the inner retinal cell layers, such as the RGC layer. Intriguingly, previous studies in genetically modified animal models of atherosclerosis, including ApoE-/- mice, reported on pathological changes in outer retinal layers, such as lipoidal degenerations and basal deposits in the Bruch's membrane that resemble alterations observed in ageing human eyes, with some functional and morphologic alterations similar to those found in age-related macular degeneration [60-63]. In support of this concept, some studies in humans found a positive association of serum cholesterol levels with age-related macular degeneration $[64,65]$.

In contrast, the effects of apolipoprotein E deficiency on RGC survival have not been studied in detail so far. A recent meta-analysis reported that hyperlipidemia was associated with an increased risk of glaucoma, a disease characterized by progressive RGC and visual field loss [12]. However, the original studies included in the meta-analysis displayed highly heterogenic results [12]. Also, studies on the association of apolipoprotein E gene polymorphisms with glaucoma reported heterogenic results [66-69]. Interestingly, a study in mice found that apolipoprotein E deficiency was even protective against RGC death induced by elevated intraocular pressure or optic nerve crush [70]. In the present study, 12month-old ApoE-/- mice and age-matched wild-type controls had a similar total cell number in the RGC layer, which comprises RGCs, displaced amacrine cells, vascular cells, and glial cells. Moreover, no differences in optic nerve axon number, which reflects the number of RGCs, have been detected, suggesting that apolipoprotein E deficiency has no effect of RGC viability. The mRNA expression data of the present study, however, revealed increased expression levels for HIF-1 $\alpha$ and 
VEGF- $A$ together with increased levels for NOX1 and NOX2 indicating that abnormal vascular function in the retina may have triggered hypoxia and ROS generation. However, also a variety of antioxidant redox genes was shown to be upregulated in the retina of ApoE-/- mice, suggesting that compensatory antioxidant pathways have been activated, which may have buffered excessive ROS and RNS generation and, thus, their potential deleterious effects on cell viability.

Apart from its role in the regulation of cholesterol homeostasis in the peripheral circulation, apolipoprotein $\mathrm{E}$ is expressed in the central nervous system including the retina and optic nerve, where it takes part in cholesterol transport and intracellular exchange of metabolites between neurons and glial cells [71-73]. One study reported that activated retinal glial cells promote neurite outgrowth in RGCs via involvement of apolipoprotein E [73]. However, studies of retinal histology and function have shown only minor changes in ApoE-/- mice [74, 75]. In support of this concept, detailed neurocognitive and retinal studies in a 40 -year-old patient with severe dysbetalipoproteinemia due to total absence of apolipoprotein $\mathrm{E}$ failed to demonstrate any functional and morphological defects [76]. These findings suggest that redundant mechanisms exist in the retina to compensate for the lack of apolipoprotein E.

\section{Conclusions}

Our study demonstrates that chronic apolipoprotein E deficiency promotes endothelial dysfunction in retinal arterioles. The presented data also suggest that LOX-1, NOX2, and ROS, but not RNS, are involved in this process. Although the mRNA expression for prooxidant enzymes was increased in the retina of ApoE-/- mice, mRNA for antioxidant enzymes was also upregulated, indicating that oxidative stress in retinal tissue appears to be quenched by antioxidant mechanisms, which results in preservation of RGC viability. Hence, our data also suggest that apolipoprotein E deficiency and endothelial dysfunction of the retinal vasculature are not deleterious to RGCs, at least in the absence of additional pathophysiological stimuli.

\section{Abbreviations}

$\begin{array}{ll}\text { ApoE-/-: } & \text { Apolipoprotein E-deficient mouse } \\ \text { DAPI: } & 4^{\prime}, 6 \text {-Diamidino-2-phenylindole } \\ \text { DHE: } & \text { Dihydroethidium } \\ \text { EDHF: } & \text { Endothelium-derived hyperpolarizing factor } \\ \text { eNOS: } & \text { Endothelial nitric oxide synthase } \\ \text { GPx1: } & \text { Glutathinone peroxidase } 1 \\ \text { HIF-1 } \alpha: & \text { Hypoxia-inducible factior-1 } \alpha \\ \text { HO-1: } & \text { Heme oxygenase-1 } \\ \text { iNOS: } & \text { Inducible nitric oxide synthase } \\ \text { IOP: } & \text { Intraocular pressure } \\ \text { nNOS: } & \text { Neuronal nitric oxide synthase } \\ \text { NOX: } & \text { Nicotinamide adenine dinucleotide phosphate } \\ & \text { oxidase } \\ \text { LDL: } & \text { Low-density lipoprotein } \\ \text { LOX-1: } & \text { Lectin-like oxidized low-density lipoprotein } \\ & \text { receptor-1 }\end{array}$

PBS: $\quad$ Phosphate-buffered saline

RGC: Retinal ganglion cell

RNS: $\quad$ Reactive nitrogen species

ROS: $\quad$ Reactive oxygen species

SNP: $\quad$ Sodium nitroprusside

SOD: $\quad$ Superoxide dismutase

TNF- $\alpha$ : Tumor necrosis factor alpha

U46619: 9,11-Dideoxy-9 $\alpha, 11 \alpha$-methanoepoxy prostaglandin F $2 \alpha$

VEGF-A: Vascular endothelial growth factor a.

\section{Data Availability}

The data used to support the findings of this study are available from the corresponding author upon request.

\section{Disclosure}

Part of this study will be presented in the $\mathrm{PhD}$ thesis of Jenia Kouchek Zadeh. Part of the data in the manuscript were presented as a poster at the congress of the Annual Meeting of the Association for Research in Vision and Ophthalmology (ARVO) 2014 in Orlando, FL, USA. The conference abstract was published in IOVS 2014, Vol.55, 4352.

\section{Conflicts of Interest}

The authors state that there is no conflict of interests.

\section{Authors' Contributions}

A.G. and H.L. designed the study. A.G., A.M., C.Y., J.K.Z., M.B.Z., P.L., C.B., and N.X. conducted the experiments. A.G., J.K.Z., M.B.Z., and N.X. analyzed data. A.D., C.B., M.O., and N.P. contributed essential materials and reagents. A.G. and J.K.Z. wrote the manuscript. All authors read and approved the final manuscript.

\section{Acknowledgments}

We are grateful to Ms. Gisela Reifenberg, Department of Pharmacology, University Medical Center, Johannes Gutenberg University Mainz, for her technical assistance with PCR; to Ms. Karin Molter, Institute of Pathology, University Medical Center, Johannes Gutenberg University Mainz, for her expert assistance with optic nerve embedding procedures; and to Ms. Jessica Rudolph for her technical assistance with blood pressure measurements. A.G. and H.L. received financial support for the work by the intramural Science Transfer Program of the University Medical Center Mainz.

\section{References}

[1] L. J. Mundal, J. Igland, M. B. Veierød et al., "Impact of age on excess risk of coronary heart disease in patients with familial hypercholesterolaemia," Heart, vol. 104, no. 19, pp. 16001607, 2018.

[2] J. P. Appleton, P. Scutt, N. Sprigg, and P. M. Bath, "Hypercholesterolaemia and vascular dementia," Clinical Science, vol. 131, no. 14, pp. 1561-1578, 2017. 
[3] M. G. Wong, C. Wanner, J. Knight, and V. Perkovic, "Lowering cholesterol in chronic kidney disease: is it safe and effective?," European Heart Journal, vol. 36, no. 43, pp. 2988-2995, 2015.

[4] H. Mollazadeh, F. Carbone, F. Montecucco, M. Pirro, and A. Sahebkar, "Oxidative burden in familial hypercholesterolemia," Journal of Cellular Physiology, vol. 233, no. 8, pp. 5716-5725, 2018.

[5] U. Forstermann, N. Xia, and H. Li, "Roles of vascular oxidative stress and nitric oxide in the pathogenesis of atherosclerosis," Circulation Research, vol. 120, no. 4, pp. 713-735, 2017.

[6] M. Reimann, S. Prieur, B. Lippold et al., "Retinal vessel analysis in hypercholesterolemic patients before and after LDL apheresis," Atherosclerosis Supplements, vol. 10, no. 5, pp. 39-43, 2009.

[7] M. Sharifizad, K. J. Witkowska, G. C. Aschinger et al., "Factors determining flicker-induced retinal vasodilation in healthy subjects," Investigative Ophthalmology \& Visual Science, vol. 57, no. 7, pp. 3306-3312, 2016.

[8] S. Seshadri, S. E. Karimzad, H. Shokr, and D. Gherghel, "Retinal vascular function in asymptomatic individuals with a positive family history of cardiovascular disease," Acta Ophthalmologica, vol. 96, no. 8, pp. e956-e962, 2018.

[9] N. Cheung, L. Lim, J. J. Wang et al., "Prevalence and risk factors of retinal arteriolar emboli: the Singapore Malay Eye Study," American Journal of Ophthalmology, vol. 146, no. 4, pp. 620-624, 2008.

[10] T. Stojakovic, H. Scharnagl, W. März, B. R. Winkelmann, B. O. Boehm, and O. Schmut, "Low density lipoprotein triglycerides and lipoprotein(a) are risk factors for retinal vascular occlusion," Clinica Chimica Acta, vol. 382, no. 1-2, pp. 77-81, 2007.

[11] R. Marcucci, A. Sodi, B. Giambene et al., "Cardiovascular and thrombophilic risk factors in patients with retinal artery occlusion," Blood Coagulation \& Fibrinolysis, vol. 18, no. 4, pp. 321326, 2007.

[12] S. Wang and X. Bao, "Hyperlipidemia, blood lipid level, and the risk of glaucoma: a meta-analysis," Investigative Ophthalmology \& Visual Science, vol. 60, no. 4, pp. 1028-1043, 2019.

[13] H. A. Quigley and A. T. Broman, "The number of people with glaucoma worldwide in 2010 and 2020," The British Journal of Ophthalmology, vol. 90, no. 3, pp. 262-267, 2006.

[14] Y. C. Tham, X. Li, T. Y. Wong, H. A. Quigley, T. Aung, and C. Y. Cheng, "Global prevalence of glaucoma and projections of glaucoma burden through 2040: a systematic review and meta-analysis," Ophthalmology, vol. 121, no. 11, pp. 20812090, 2014.

[15] M. Yoshida, S. Kunimatsu-Sanuki, K. Omodaka, and T. Nakazawa, "Structure/function relationship between widescan binocular OCT images and the integrated visual field in glaucoma patients," Clinical \& Experimental Ophthalmology, vol. 44, no. 6, pp. 526-528, 2016.

[16] H. Resch, G. Garhofer, G. Fuchsjäger-Mayrl, A. Hommer, and L. Schmetterer, "Endothelial dysfunction in glaucoma," Acta Ophthalmologica, vol. 87, no. 1, pp. 4-12, 2009.

[17] J. Barthelmes, M. P. Nägele, V. Ludovici, F. Ruschitzka, I. Sudano, and A. J. Flammer, "Endothelial dysfunction in cardiovascular disease and Flammer syndrome-similarities and differences," The EPMA Journal, vol. 8, no. 2, pp. 99-109, 2017.

[18] Y. Nakashima, A. S. Plump, E. W. Raines, J. L. Breslow, and R. Ross, "ApoE-deficient mice develop lesions of all phases of atherosclerosis throughout the arterial tree," Arteriosclerosis and Thrombosis, vol. 14, no. 1, pp. 133-140, 1994.

[19] R. Sun, J. Tian, J. Zhang, L. Wang, J. Guo, and Y. Liu, "Monitoring inflammation injuries in the progression of atherosclerosis with contrast enhanced ultrasound molecular imaging," PLoS One, vol. 12, no. 10, article e0186155, 2017.

[20] Q. N. Dinh, S. Chrissobolis, H. Diep et al., "Advanced atherosclerosis is associated with inflammation, vascular dysfunction and oxidative stress, but not hypertension," Pharmacological Research, vol. 116, pp. 70-76, 2017.

[21] P. Wohlfart, H. Xu, A. Endlich et al., "Antiatherosclerotic effects of small-molecular-weight compounds enhancing endothelial nitric-oxide synthase (eNOS) expression and preventing eNOS uncoupling," The Journal of Pharmacology and Experimental Therapeutics, vol. 325, no. 2, pp. 370-379, 2008.

[22] A. Gericke, J. J. Sniatecki, E. Goloborodko et al., "Identification of the muscarinic acetylcholine receptor subtype mediating cholinergic vasodilation in murine retinal arterioles," Investigative Ophthalmology \& Visual Science, vol. 52, no. 10, pp. 7479-7484, 2011.

[23] A. Gericke, E. Goloborodko, N. Pfeiffer, and C. Manicam, "Preparation steps for measurement of reactivity in mouse retinal arterioles Ex Vivo," Journal of Visualized Experiments, vol. 135, no. 135, 2018.

[24] M. Oelze, A. Warnholtz, J:. Faulhaber et al., "NADPH oxidase accounts for enhanced superoxide production and impaired endothelium-dependent smooth muscle relaxation in BK $\beta 1^{-1-}$ Mice," Arteriosclerosis, Thrombosis, and Vascular Biology, vol. 26, no. 8, pp. 1753-1759, 2006.

[25] P. Laspas, M. B. Zhutdieva, C. Brochhausen et al., "The $M_{1}$ muscarinic acetylcholine receptor subtype is important for retinal neuron survival in aging mice," Scientific Reports, vol. 9, no. 1, article 5222, 2019.

[26] J. K. Zadeh, R. Ruemmler, E. K. Hartmann et al., "Responses of retinal arterioles and ciliary arteries in pigs with acute respiratory distress syndrome (ARDS)," Experimental Eye Research, vol. 184, pp. 152-161, 2019.

[27] J. K. Zadeh, A. Garcia-Bardon, E. K. Hartmann et al., "Shorttime ocular ischemia induces vascular endothelial dysfunction and ganglion cell loss in the pig retina," International Journal of Molecular Sciences, vol. 20, no. 19, article 4685, 2019.

[28] N. Xia, S. Horke, A. Habermeier et al., "Uncoupling of endothelial nitric oxide synthase in perivascular adipose tissue of diet-induced obese mice," Arteriosclerosis, Thrombosis, and Vascular Biology, vol. 36, no. 1, pp. 78-85, 2016.

[29] P. Laspas, O. W. Gramlich, H. D. Müller et al., "Autoreactive antibodies and loss of retinal ganglion cells in rats induced by immunization with ocular antigens," Investigative Ophthalmology \& Visual Science, vol. 52, no. 12, pp. 8835-8848, 2011.

[30] P. Laspas, E. Goloborodko, J. J. Sniatecki et al., "Role of nitric oxide synthase isoforms for ophthalmic artery reactivity in mice," Experimental Eye Research, vol. 127, pp. 1-8, 2014.

[31] P. Laspas, J. J. Sniatecki, C. Brochhausen et al., "Effect of the $\mathrm{M}_{1}$ muscarinic acetylcholine receptor on retinal neuron number studied with gene-targeted mice," Journal of Molecular Neuroscience, vol. 56, no. 2, pp. 472-479, 2015.

[32] A. J. Kattoor, S. H. Kanuri, and J. L. Mehta, "Role of ox-LDL and LOX-1 in atherogenesis," Current Medicinal Chemistry, vol. 26, no. 9, pp. 1693-1700, 2019. 
[33] T. Aoyama, T. Sawamura, Y. Furutani et al., "Structure and chromosomal assignment of the human lectin-like oxidized low-density-lipoprotein receptor-1 (LOX-1) gene," The Biochemical Journal, vol. 339, no. 1, Part 1, pp. 177-184, 1999.

[34] L. Pérez, A. Vallejos, C. Echeverria, D. Varela, C. CabelloVerrugio, and F. Simon, "OxHDL controls LOX-1 expression and plasma membrane localization through a mechanism dependent on NOX/ROS/NF- $\kappa \mathrm{B}$ pathway on endothelial cells," Laboratory Investigation, vol. 99, no. 3, pp. 421-437, 2019.

[35] N. J. Alp, M. A. McAteer, J. Khoo, R. P. Choudhury, and K. M. Channon, "Increased endothelial tetrahydrobiopterin synthesis by targeted transgenic GTP-cyclohydrolase I overexpression reduces endothelial dysfunction and atherosclerosis in ApoE-knockout mice," Arteriosclerosis, Thrombosis, and Vascular Biology, vol. 24, no. 3, pp. 445-450, 2004.

[36] M. Simionescu, "Implications of early structural-functional changes in the endothelium for vascular disease," Arteriosclerosis, Thrombosis, and Vascular Biology, vol. 27, no. 2, pp. 266-274, 2007.

[37] E. Rossitch Jr., E. Alexander 3rd, P. M. Black, and J. P. Cooke, " $\mathrm{L}$-arginine normalizes endothelial function in cerebral vessels from hypercholesterolemic rabbits," The Journal of Clinical Investigation, vol. 87, no. 4, pp. 1295-1299, 1991.

[38] J. Kitayama, F. M. Faraci, S. R. Lentz, and D. D. Heistad, "Cerebral vascular dysfunction during hypercholesterolemia," Stroke, vol. 38, no. 7, pp. 2136-2141, 2007.

[39] K. Yamashiro, A. B. Milsom, J. Duchene et al., "Alterations in nitric oxide and endothelin-1 bioactivity underlie cerebrovascular dysfunction in ApoE-deficient mice," Journal of Cerebral Blood Flow and Metabolism, vol. 30, no. 8, pp. 1494-1503, 2010.

[40] A. A. Miller, T. M. de Silva, C. P. Judkins, H. Diep, G. R. Drummond, and C. G. Sobey, "Augmented superoxide production by Nox2-containing NADPH oxidase causes cerebral artery dysfunction during hypercholesterolemia," Stroke, vol. 41, no. 4, pp. 784-789, 2010.

[41] O. de Montgolfier, A. Pinçon, P. Pouliot et al., "High systolic blood pressure induces cerebral microvascular endothelial dysfunction, neurovascular unit damage, and cognitive decline in mice," Hypertension, vol. 73, no. 1, pp. 217-228, 2019.

[42] S. H. Tsai, W. Xie, M. Zhao, Rosa RH Jr, T. W. Hein, and L. Kuo, "Alterations of ocular hemodynamics impair ophthalmic vascular and neuroretinal function," The American Journal of Pathology, vol. 188, no. 3, pp. 818-827, 2018.

[43] V. P. Costa, A. Harris, D. Anderson et al., "Ocular perfusion pressure in glaucoma," Acta Ophthalmologica, vol. 92, no. 4, pp. e252-e266, 2014.

[44] L. V. d'Uscio, M. Barton, S. Shaw, and T. F. Lüscher, "Chronic $\mathrm{ET}_{\mathrm{A}}$ receptor blockade prevents endothelial dysfunction of small arteries in apolipoprotein E-deficient mice," Cardiovascular Research, vol. 53, no. 2, pp. 487-495, 2002.

[45] J. Ketonen, S. Merasto, I. Paakkari, and E. M. Mervaala, "High sodium intake increases vascular superoxide formation and promotes atherosclerosis in apolipoprotein E-deficient mice," Blood Pressure, vol. 14, no. 6, pp. 373-382, 2005.

[46] C. J. Hartley, A. K. Reddy, S. Madala et al., "Hemodynamic changes in apolipoprotein E-knockout mice," American Journal of Physiology-Heart and Circulatory Physiology, vol. 279, no. 5, pp. H2326-H2334, 2000.
[47] T. Beleznai, H. Takano, C. Hamill et al., "Enhanced $\mathrm{K}^{+}$-channel-mediated endothelium-dependent local and conducted dilation of small mesenteric arteries from ApoE $E^{-/-}$mice," Cardiovascular Research, vol. 92, no. 2, pp. 199-208, 2011.

[48] S. E. Wolfle and C. de Wit, "Intact endothelium-dependent dilation and conducted responses in resistance vessels of hypercholesterolemic mice in vivo," Journal of Vascular Research, vol. 42, no. 6, pp. 475-482, 2005.

[49] A. Gericke, E. Goloborodko, J. J. Sniatecki, A. Steege, L. Wojnowski, and N. Pfeiffer, "Contribution of nitric oxide synthase isoforms to cholinergic vasodilation in murine retinal arterioles," Experimental Eye Research, vol. 109, pp. 60-66, 2013.

[50] A. Gericke, I. Wolff, A. Musayeva et al., "Retinal arteriole reactivity in mice lacking the endothelial nitric oxide synthase (eNOS) gene," Experimental Eye Research, vol. 181, pp. 150156, 2019.

[51] G. Garhöfer, C. Zawinka, H. Resch, P. Kothy, L. Schmetterer, and G. T. Dorner, "Reduced response of retinal vessel diameters to flicker stimulation in patients with diabetes," The British Journal of Ophthalmology, vol. 88, no. 7, pp. 887-891, 2004.

[52] S. T. Venkataraman, C. Hudson, R. Rachmiel et al., "Retinal arteriolar vascular reactivity in untreated and progressive primary open-angle glaucoma," Investigative Ophthalmology \& Visual Science, vol. 51, no. 4, pp. 2043-2050, 2010.

[53] B. S. Cheema, H. S. kohli, R. Sharma, A. Bhansali, and M. Khullar, "Endothelial nitric oxide synthase gene polymorphism and type 2 diabetic retinopathy among Asian Indians," Acta Diabetologica, vol. 49, no. 6, pp. 481-488, 2012.

[54] I. Cilenšek, S. Mankoč, M. G. Petrovič, and D. Petrovič, "The $4 \mathrm{a} / 4 \mathrm{a}$ genotype of the VNTR polymorphism for endothelial nitric oxide synthase (eNOS) gene predicts risk for proliferative diabetic retinopathy in Slovenian patients (Caucasians) with type 2 diabetes mellitus," Molecular Biology Reports, vol. 39, no. 6, pp. 7061-7067, 2012.

[55] S. Zhao, T. Li, B. Zheng, and Z. Zheng, "Nitric oxide synthase 3 (NOS3) 4b/a, T-786C and G894T polymorphisms in association with diabetic retinopathy susceptibility: a meta-analysis," Ophthalmic Genetics, vol. 33, no. 4, pp. 200-207, 2012.

[56] J. W. Jeoung, D. M. Kim, S. Oh, J. S. Lee, S. S. Park, and J. Y. Kim, "The relation between endothelial nitric oxide synthase polymorphisms and normal tension glaucoma," Journal of Glaucoma, vol. 26, no. 11, pp. 1030-1035, 2017.

[57] Y. Xiang, Y. Dong, X. Li, and X. Tang, "Association of common variants in eNOS gene with primary open angle glaucoma: a meta-analysis," Journal of Ophthalmology, vol. 2016, Article ID 1348347, 11 pages, 2016.

[58] Q. Li, A. Verma, P. Y. Han et al., "Diabetic eNOS-knockout mice develop accelerated retinopathy," Investigative Ophthalmology \& Visual Science, vol. 51, no. 10, pp. 5240-5246, 2010.

[59] D.-Y. Yu, S. J. Cringle, P. K. Yu et al., "Retinal capillary perfusion: spatial and temporal heterogeneity," Progress in Retinal and Eye Research, vol. 70, pp. 23-54, 2019.

[60] A. C. Provost, L. Vede, K. Bigot et al., "Morphologic and electroretinographic phenotype of SR-BI knockout mice after a long-term atherogenic diet," Investigative Ophthalmology \& Visual Science, vol. 50, no. 8, pp. 3931-3942, 2009.

[61] S. Dithmar, C. A. Curcio, N. A. le, S. Brown, and H. E. Grossniklaus, "Ultrastructural changes in Bruch's membrane of apolipoprotein E-deficient mice," Investigative Ophthalmology \& Visual Science, vol. 41, no. 8, pp. 2035-2042, 2000. 
[62] G. Malek, L. V. Johnson, B. E. Mace et al., “Apolipoprotein E allele-dependent pathogenesis: a model for age-related retinal degeneration," Proceedings of the National Academy of Sciences of the United States of America, vol. 102, no. 33, pp. 11900-11905, 2005.

[63] M. Rudolf, B. Winkler, Z. Aherrahou, L. C. Doehring, P. Kaczmarek, and U. Schmidt-Erfurth, "Increased expression of vascular endothelial growth factor associated with accumulation of lipids in Bruch's membrane of LDL receptor knockout mice," The British Journal of Ophthalmology, vol. 89, no. 12, pp. 1627-1630, 2005.

[64] J. A. Mares-Perlman, W. E. Brady, R. Klein, G. VandenLangenberg, B. E. Klein, and M. Palta, "Dietary fat and age-related maculopathy," Archives of Ophthalmology, vol. 113, no. 6, pp. 743-748, 1995.

[65] L. Hyman, A. P. Schachat, Q. He, M. C. Leske, and for the AgeRelated Macular Degeneration Risk Factors Study Group, "Hypertension, cardiovascular disease, and age-related macular Degeneration," Archives of Ophthalmology, vol. 118, no. 3, pp. 351-358, 2000.

[66] T. Ressiniotis, P. G. Griffiths, M. Birch, S. Keers, and P. F. Chinnery, "The role of apolipoprotein E gene polymorphisms in primary open-angle glaucoma," Archives of Ophthalmology, vol. 122, no. 2, pp. 258-261, 2004.

[67] M. Zetterberg, G. Tasa, M. S. Palmér et al., “Apolipoprotein E polymorphisms in patients with primary open-angle glaucoma," American Journal of Ophthalmology, vol. 143, no. 6, pp. 1059-1060, 2007.

[68] F. Mabuchi, S. Tang, D. Ando et al., "The apolipoprotein E gene polymorphism is associated with open angle glaucoma in the Japanese population," Molecular Vision, vol. 11, pp. 609-612, 2005.

[69] C. Y. Lam, B. J. Fan, D. Y. Wang et al., “Association of apolipoprotein E polymorphisms with normal tension glaucoma in a Chinese population," Journal of Glaucoma, vol. 15, no. 3, pp. 218-222, 2006.

[70] K. Omodaka, K. M. Nishiguchi, M. Yasuda et al., "Neuroprotective effect against axonal damage-induced retinal ganglion cell death in apolipoprotein E-deficient mice through the suppression of kainate receptor signaling," Brain Research, vol. 1586, pp. 203-212, 2014.

[71] P. S. Hauser, V. Narayanaswami, and R. O. Ryan, "Apolipoprotein E: from lipid transport to neurobiology," Progress in Lipid Research, vol. 50, no. 1, pp. 62-74, 2011.

[72] A. Amaratunga, C. R. Abraham, R. B. Edwards, J. H. Sandell, B. M. Schreiber, and R. E. Fine, "Apolipoprotein E is synthesized in the retina by Müller glial cells, secreted into the vitreous, and rapidly transported into the optic nerve by retinal ganglion cells," The Journal of Biological Chemistry, vol. 271, no. 10, pp. 5628-5632, 1996.

[73] B. Lorber, M. Berry, M. R. Douglas, T. Nakazawa, and A. Logan, "Activated retinal glia promote neurite outgrowth of retinal ganglion cells via apolipoprotein E," Journal of Neuroscience Research, vol. 87, no. 12, pp. 2645-2652, 2009.

[74] A. Saadane, A. Petrov, N. Mast et al., "Mechanisms that minimize retinal impact of apolipoprotein E absence," Journal of Lipid Research, vol. 59, no. 12, pp. 2368-2382, 2018.
[75] J. M. Ong, N. C. Zorapapel, K. A. Rich et al., "Effects of cholesterol and apolipoprotein E on retinal abnormalities in ApoEdeficient mice," Investigative Ophthalmology \& Visual Science, vol. 42, no. 8, pp. 1891-1900, 2001.

[76] A. C. Mak, C. R. Pullinger, L. F. Tang et al., "Effects of the absence of apolipoprotein e on lipoproteins, neurocognitive function, and retinal function," JAMA Neurology, vol. 71, no. 10, pp. 1228-1236, 2014. 


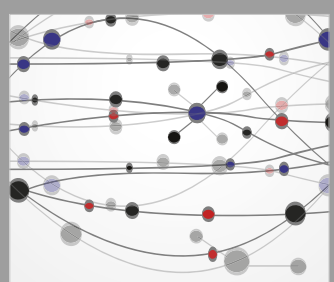

The Scientific World Journal
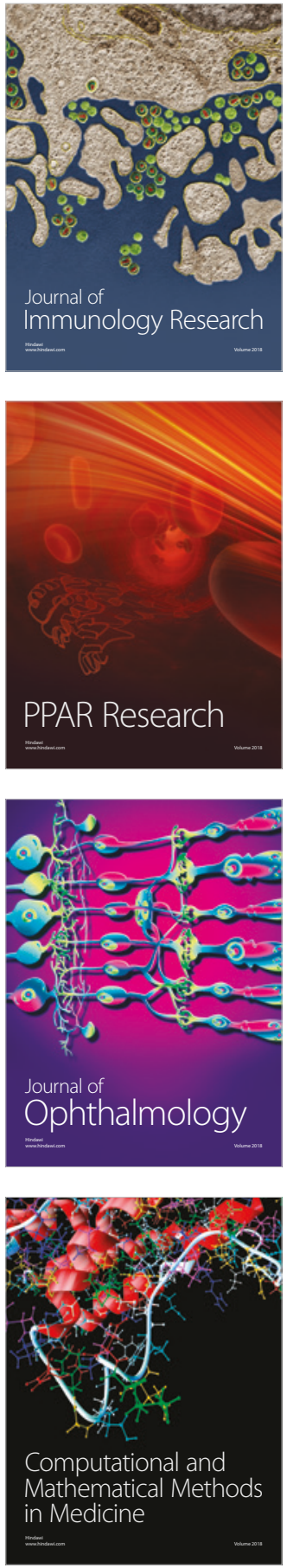

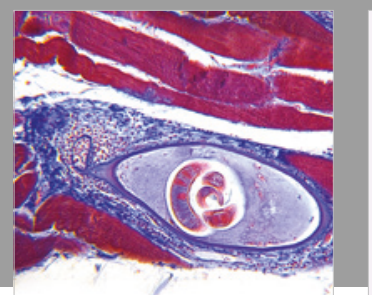

Gastroenterology Research and Practice

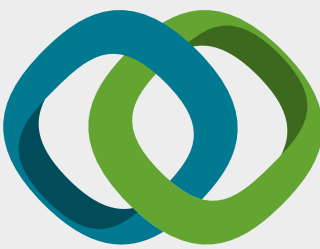

\section{Hindawi}

Submit your manuscripts at

www.hindawi.com
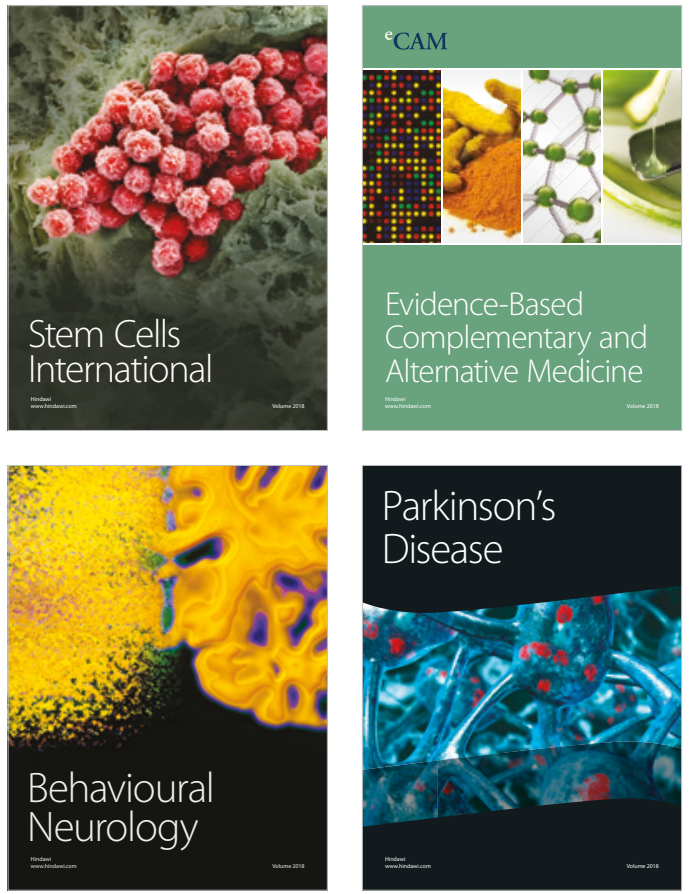

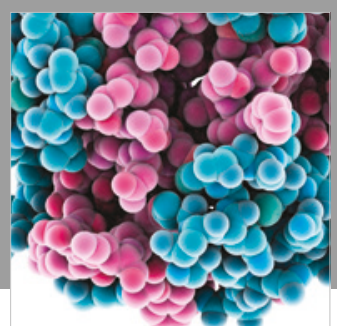

ournal of

Diabetes Research

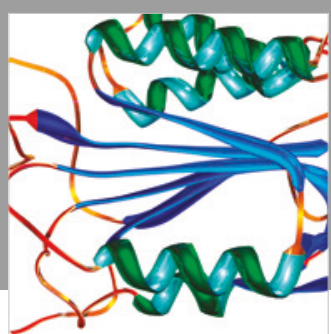

Disease Markers
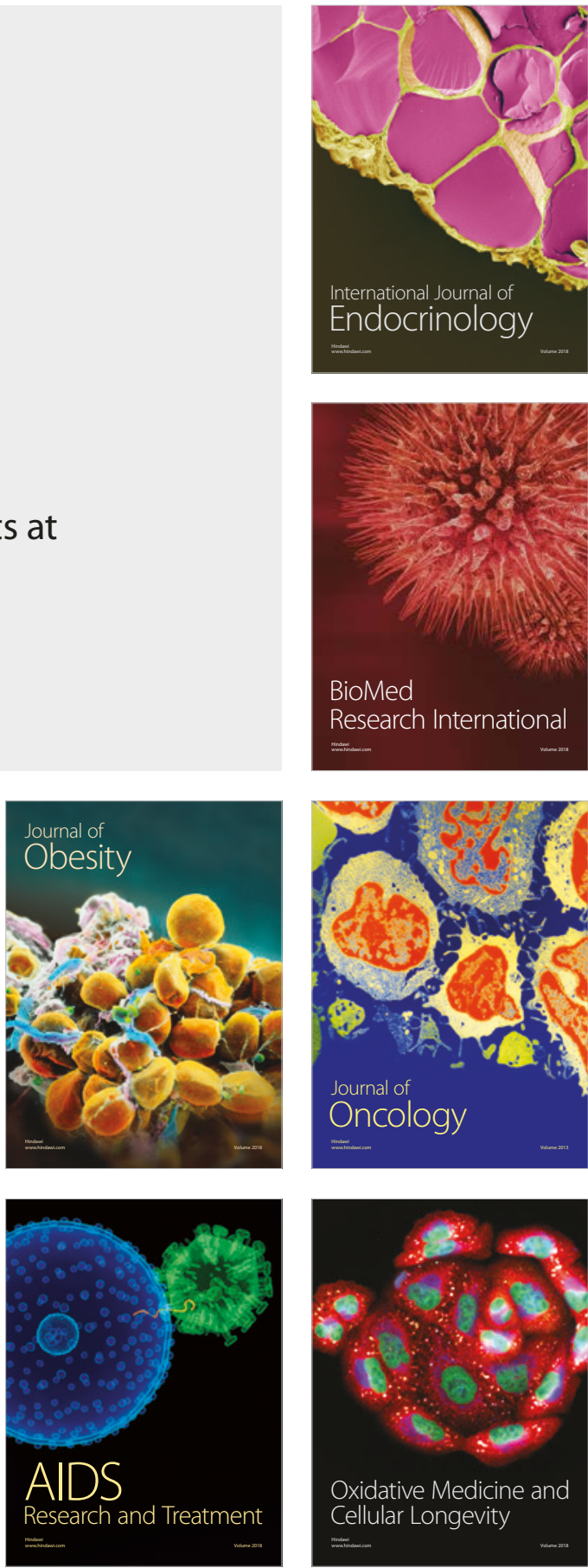